\title{
First record of the harpacticoid genus Nitocrellopsis (Copepoda, Ameiridae) in Australia, with descriptions of three new species
}

\author{
Tomislav Karanovic ${ }^{1,2 *}$ \\ ${ }^{1}$ University of Tasmania, Institute for Marine and Antarctic Studies, Private Bag 5, Hobart 7001, Tasmania, Australia \\ ${ }^{2}$ Hanyang University, Department of Life Sciences, Seoul 133-791, South Korea
}

Received 23 February 2010; Accepted 5 August 2010

\begin{abstract}
Three new freshwater ameirid species were discovered in the Western Australian subterranean habitats and described in this paper. They all proved to belong to the genus Nitocrellopsis Galassi, De Laurentiis \& Dole-Olivier, 1999, representing the first record of this genus in Australia. Nitocrellopsis operculata sp. nov. was collected in 2003 in the Pilbara region, during the Pilbara Regional Survey, led by the Western Australian Department of Environment and Conservation (DEC). It can be distinguished from all other congeners by the reduced armature of the antennal exopod, which is an autapomorphic feature. Also, no other species of Nitocrellopsis has cuticular windows on prosomal or urosomal somites, or six elements on the third exopodal segment of the second leg. Nitocrellopsis halsei sp. nov. and N. pinderi sp. nov. are sister-species, collected in 2007 in the neighbouring Yilgarn region, by the private environmental consulting company Bennelongia Pty Ltd. Numerous morphological similarities include somite ornamentation, armature patterns of the swimming legs and the fifth leg, as well as the shape and armature of the antennula, antenna and almost all mouth appendages, while the main differences between the two are observed in the body size and habitus appearance, caudal rami shape and size, presence/absence of large lateral pores on the fourth pedigerous somite, number of spinules on the anal operculum, number of setae on the madibular endopod, and shape of the exopod of the fifth leg. Although they differ from any other congener by a combination of characters, no significant autapomorphic features were observed. In order to find a more natural allocation of these three species, a cladistic analysis is performed on all current members of Nitocrellopsis and three outgroup taxa, based on 45 morphological characters. The resulting cladogram shows that the ingroup is well defined by at least four synapomorphies, but the Australian species from the two regions are only remotely related to each other, showing the importance of looking at small-scale patterns when inferring Gondwanan biogeography. Three sister-species pairs are recognized in the genus and a key to all 12 members is provided.
\end{abstract}

Key words: Cladistics / phylogeny / Pilbara / stygofauna / subterranean / Tethyan relics / Western Australia / Yilgarn / zoogeography

\section{Introduction}

Arid regions of Western Australia, and especially patchy habitats associated with carbonate rich sediments, known as calcretes, are becoming known as a significant hot-spot for stygofauna diversity on a global scale (Humphreys, 2001, 2006, 2008). Although most of these discoveries are fairly recent, a number of taxa have already been described and many more are in press or in preparation. Our knowledge of diving beetles now amounts to more than 80 described subterranean species (Watts and

\footnotetext{
*Corresponding author: Tomislav.Karanovic@utas .edu. au;
} tomislav@hanyang.ac.kr
Humphreys, 2006), while ostracod crustaceans are even more diverse (Karanovic, 2007). Other speciose groups include bathynellaceans (Cho et al., 2006a, 2006b), amphipods (Finston et al., 2007), and isopods (Wilson, 2008), but some others are very poorly studied, although regularly collected in great numbers (water mites and oligochaetes for example). Copepods proved to be one of the most abundant and diverse subterranean groups here, containing both some ancient lineages and recent invaders, short range endemics and relatively widely distributed species (Nicholls, 1945a, 1945b; Pesce and De Laurentiis, 1996; Pesce et al., 1996a, 1996b; De Laurentiis et al., 1999, 2001; Jaume and Humphreys, 2001; Jaume et al., 2001; Karanovic et al., 2001; Karanovic and Pesce, 2002; 
Lee and Huys, 2002; Karanovic, 2003, 2004a, 2004b, 2005, 2006, 2008; Tang et al., 2008; Karanovic and Eberhard, 2009; Karanovic and Hancock, 2009; Karanovic and Tang, 2009; Tang and Knott, 2009). In Western Australia it is necessary for any new development that potentially impacts on groundwater to be preceded by biological surveys of groundwater biodiversity. For this reason in the last couple of years many private environmental consulting agencies, as well as individuals from several academic institutions, continued to collect stygofauna in Australia and most of the copepod material collected was entrusted to me for identification. Among many other ameirids, three new species proved to belong to the genus Nitocrellopsis Galassi, De Laurentiis \& DoleOlivier, 1999, which was previously unknown in Australia. They are described in this paper. One of them was collected in 2003 in the Pilbara region, during the large Pilbara Regional Survey, led by the Western Australian Department of Environment and Conservation (DEC). This survey was motivated by the need to assess the likely environmental impacts of economically important natural resources development projects (mostly mining) on stygofauna, and most copepods were described by Karanovic (2006). Two others species of Nitocrellopsis were collected in 2007 in the neighbouring Yilgarn region, by the private environmental consulting company Bennelongia Pty Ltd.

The genus name Nitocrellopsis was established by Petkovski (1976) in an attempt to revise the genus Nitocrella Chappuis, 1924. The latter was established by Chappuis (1924) to accommodate a new species from Serbia, Nitocrella hirta Chappuis, 1924, but in subsequent years many authors (including Chappuis himself) have used the genus as a taxonomic repository, which blurred its boundaries in a remarkable way. Even after Lang's (1965) revised taxonomic concept, Nitocrella continued to accumulate a large number of not very closely related new species, which prompted Petkovski (1976) to subdivide the genus even further. He defined Nitocrellopsis for those species of Nitocrella with the endopod of the fourth leg two-segmented and the endopods of the second and thid legs three-segemented, i.e. with the swimming legs segmentation formula (exopod/endopod): $3 / 3,3 / 3,3 / 3$, $3 / 2$. He also compiled a key to the following three species recognized by him as valid members of the genus at the time: Nitocrellopsis intermedia (Chappuis, 1937), described from both sexes from interstitial waters near Skopje in Yugoslavia (now FYR Macedonia) by Chappuis (1937) and later on discovered in Bulgaria by MichailovaNeikova (1964); N. elegans (Chappuis and Rouch, 1959), described from females only from a tunnel in France by Chappuis and Rouch (1959), and males discovered later on from the same locality by Rouch (1964); and N. ioneli (Dumont and Decraemer, 1974), described from both sexes from a well in the presaharan Atlas Mountins of Morocco by Dumont and Decraemer (1974). However, Petkovski (1976) did not designate a type species, which according to the current International Code of Zoological Nomenclature (ICZN, 1999, Article 13.3) means that the generic name was unavailable. In order to be available every new genus-group name published after 1930 must be accompanied by the fixation of a type species, in addition to satisfying the provisions of Article 13.1, i.e. providing or citing a description or definition of the genus.

Notwithstanding that, three new species of this genus have been described subsequently with the generic authorship being attributed to Petkovski (1976). Rouch (1987) described N. petkovskii Rouch, 1987 from both sexes from subterranean waters near Beni Amrane in Algeria. Cottarelli and Forniz (1993) described two very closely related species from interstitial freshwaters of two Greek islands in the Mediterranean Sporades: $N$. hellenica Cotarelli \& Forniz, 1993 was described from the island of Kos, while $N$. hippocratis Cottarelli \& Forniz, 1993 was described from a different locality in Kos and also found in the island of Tilos. Note that the authors designated the holotype of the latter species from the Kos sample, and erroneously labelled specimens from Tilos as paratypes (Cottareli and Forniz, 1993, p. 136). This is not in accordance with the International Code of Zoological Nomenclature, as the paratypes must be from the same locality and same series as the holotype (ICZN, 1999, Articles 72.4.4 and 76.1). Also note that Fiers and Iliffe (2000, p. 81) erroneously stated that each Greek species came from a different island.

Galassi et al. (1999) described another species from France, N. rouchi Galassi, De Laurentiis \& Dole-Olivier, which they designated as the type species of the genus and gave a revised diagnosis, making the generic name available with their authorship, i.e. Nitocrellopsis Galassi, De Laurentiis \& Dole-Olivier, 1999. They also re-examined the type material and gave some additional information for the following four previously known species: $N$. hellenica, N. hippocratis, $N$. ioneli, and $N$. petkovskii. On the same occasion they gave a key to all seven then known species, but they also treated all previously described species as new combinations and cited all author names in parentheses. Although neither Article 11.9.3 nor Article 51.3 of the ICZN specifically addresses this case, this was not a case of a generic name being different from the original one, since the author attribution does not form part of a name in zoological nomenclature (Article 51.1). Therefore, I think parentheses should not have been used and it was at least an overstatement to refer to such cases as new combinations. However, their generic authorship was accepted by most copepodologists in subsequent publications (see, for example, Lee and Huys, 2002; Reid et al., 2003; Karanovic, 2006; Wells, 2007; Huys, 2009; Karanovic and Hancock, 2009), although not by Fiers and Iliffe (2000) and Suárez-Morales and Iliffe (2005). I commented on the latter paper recently in Karanovic and Hancock (2009), so there is no need for repetition here, other than to make it clear that the authors were well aware of the paper by Galassi et al. (1999) and made a conscious decision to ignore its results.

Finally, Fiers and Iliffe (2000) described two new Nitocrellopsis species from two different continents. The first one was described from both sexes from a cave in Texas, US, as N. texana Fiers \& Iliffe, 2000. The second 
one, $N$. ahaggarensis Fiers \& Iliffe, 2000, came from a well at the foot of the Ahaggar Mountains in Algeria, and it was morphologically very similar to the above mentioned Moroccan $N$. ioneli. They also re-described $N$. ioneli from paratype specimens, but there is some confusion in the synonymy section that was not explained further anywhere in the text. For example, it is clear that what Van de Velde called $N$. ioneli in her unpublished Ph.D. thesis is actually $N$. ahaggarensis, but the authors also state in the synonymy section for the latter species that part of the material identified as $N$. ioneli by Dumont and Decraemer (1974) (and this is the type material from Morocco) also belongs to $N$. ahaggarensis! This would imply that $N$. ahaggarensis is distributed both in Algeria and Morocco. Yet, in the synonymy section for $N$. ioneli it was not stated that part of the original type material of Dumont and Decraemer (1974) doesn't belong to this species. Fiers and Iliffe (2000) also discussed a possible Tethyan relic distribution of the genus, although they expressed several times (for example, Fiers and Iliffe, 2000, p. 96) a concern that it "may be a typical example of [...] non-natural assemblage", probably meaning polyphyletic or paraphyletic. They however, didn't perform any phylogenetic analyses, because information on head appendages was lacking for two species and they felt that may compromise the results.

Two of the three new species described in this paper are morphologically very similar and thus probably phylogenetically closely related, which now makes three sisterspecies pairs in this group of freshwater subterranean ameirids, the other two being hellenica/hyppocratis and ioneli/ahagarrensis. I performed a cladistic analysis of all current members of Nitocrellopsis and three outgroup taxa based on 45 morphological characters, in order to find a more natural allocation of my new taxa. This was also an excellent opportunity to test the robustness of some morphological characters in the phylogenetic analyses of freshwater ameirids, with three sister-species pairs present. This is a continuation of the work done recently by Karanovic and Hancock (2009), who revised the notoriously problematic genus Stygonitocrella Reid, Hunt \& Stanley, 2003, pending a cladistic revision of the family based both on morphological and molecular characters.

\section{Material and methods}

Part of the material studied here was collected during the Pilbara regional survey, led by the Western Australian Department of Environment and Conservation (DEC), and sent for identification to me after the publication of the copepod results (Karanovic, 2006). Other material was collected by a private environmental consulting company Bennelongia Pty Ltd, although this is the same team of people who moved from government to private. Locality data and number of specimens are listed for every species separately and all material is deposited in the Western Australian Museum, Perth (WAM).

Samples were collected with haul-nets (mesh size 50 or $150 \mu \mathrm{m})$ from groundwater bores. Bores are holes mainly made by mining companies or agricultural enterprises for the purpose of water monitoring and abstraction or mineral exploration. They are usually from 5 to $20 \mathrm{~cm}$ in diameter and may be lined entirely, or in part, by PVC tubing (the casing). This tubing may be open only at the bottom, or it may be pierced at one or more levels by holes of various sizes ("slots"). The top may be securely capped or entirely open to the elements. Some bores record the water pressure at a given level in the aquifer (piezometers), while others, equipped with windmills or solar pumps, provide water for pastoral use. Many of these features are derelict. Haul-nets are actually simple plankton nets of a different size suitable for the bore; collar can range from 20 to $150 \mathrm{~mm}$ in diameter and is made of stainless steel. Weighed nets (using simple fishing leads) were lowered down into the bore with a bottle screwed on its distal part and then hauled through the water column, usually a number of times. Samples were sorted live under a dissecting microscope and the copepods picked out and fixed in $70 \%$ or $100 \%$ ethanol and assigned a field number, or were preserved in the field in $100 \%$ ethanol and sorted in a laboratory. Bores established for hydrogeological work, mineral exploration and water monitoring have prefixes or suffixes of relevance only to that drilling program. These codes are cited in the material examined for each species to aid specification of the location, although precise coordinates are also provided.

Specimens were dissected and mounted on microscope slides in Faure's medium, which was prepared following the procedure discussed by Stock and von Vaupel Klein (1996), and dissected appendages were then covered by a coverslip. For the urosome or the entire animal two human hairs were mounted between the slide and coverslip, so the parts would not be compressed. By manipulating the coverslip carefully by hand, the whole animal or a particular appendage could be positioned in different aspects, making possible the observation of morphological details. During the examination water slowly evaporated and appendages eventually remained in a completely dry Faure's medium, ready for long term depositing. All drawings were prepared using a drawing tube attached to a Leica-DMLS brighfield compound microscope, with C-PLAN achromatic objectives. Some were also reexamined with a Leica-MB2500 phase-interference compound microscope, with N-PLAN objectives. Specimens that were not drawn were examined in a mixture of equal parts of distilled water and glycerol and, after examination, were again preserved in $70 \%$ ethanol. Specimens for the scanning electron micrography were dehydrated in progressive ethanol concentrations, critical-point dried, couted in gold and observed under the LEO 1525 microscope on the in-lens detector, with working distances between 5.9 and $6.1 \mathrm{~mm}$ and accelerating voltages of 5 or $10 \mathrm{kV}$.

Morphological terminology follows Huys and Boxshall (1991), except for caudal ramus setae numbering and small differences in the spelling of some appendages (antennula, mandibula, maxillula instead of antennule, mandible, maxillule), as an attempt to standardise the terminology 
for homologous appendages in different crustacean groups. Also, for the armature formula of the swimming legs a much simplified version is used. The only reason for this is that there are a number of transitional forms between spine and seta in copepods. To avoid possible confusion I sometimes use the term "armature element" (or just "element") instead of spine or seta, especially for the fifth legs. Biospeleological terminology follows Humphreys (2000).

The cladistic analysis was performed on all 12 known species of Nitocrellopsis Galassi, De Laurentiis \& DoleOlivier, 1999 from around the world, including the three described as new in this paper. Parapseudoleptomesochra tureei Karanovic, 2006 was chosen as the outgroup. This species was described from subterranean waters of Turee Creek in the Western Australian Pilbara region, the same region one of the new Nitocrellopsis species comes from, which also shares many plesiomorphic features with $P$. tureei. However, its fourth leg exopod is threesegmented, which makes it an ideal outgroup. Another two remotely related species were added as outgroups, to additionally help in correct polarization of the character states: Biameiropsis barrowensis Karanovic, 2006 and Nitokra lacustris pacifica Yeatman, 1983. The former species was described from anchialine waters of Barrow Island (Western Australia, Pilbara region) and it is among the most primitive members of the family Ameiridae Monard, 1927, while the latter is known both from marine and freshwater habitats (see Karanovic, 2004a, 2006). Biameiropsis barrowensis was also used as the outgroup in a recent revision of the ameirid genus Stygonitocrella Reid, Hunt \& Stanley, 2003 by Karanovic and Hancock (2009), who remarked that, because of its many plesiomorphic features, this species may potentially be a suitable outgroup for any future cladistic analyses of other freshwater ameirid genera and ultimately for the revision of the family.

A total of 45 morphological characters were used in the analysis (see below). Characters were coded, optimized and weighted using the computer program WinClada, version 1.00.08 (Nixon, 2002), and then analyzed using NONA, version 2 (Goloboff, 1999). Standard coding was used in the analysis: "0" representing a presumably plesiomorphic character state and "1" a presumed apomorphy. Unknown values were coded "-" and polymorphic characters are marked in the matrix with an asterix (*). Characters related to cuticular windows (0), mandibular and maxillular endopods (6 and 7) and fifth leg endopod (40 and 41) were weighted 0.5 , all other characters were weighted 1 (average weight 0.889). All characters were coded as additive (representing ordered multistate character as a linked series of binary characters). One data matrix was created (Table 1) and characters analysed using the Rachet Island Hopper searches with the WinClada parameters: 1000 replications; 3 trees to hold; 4 characters to sample; 10 random constraint level and amb-poly= (amb- collapses a branch if the ancestor and descendant have different states under same resolutions of multistate characters or of "-"; poly= treats trees as collapsed).
Rachet is a method that searches tree space very effectively by reducing the search effort spent on generating new starting points and retaining more information from existing results of tree searches. Only characters 4 and 13 are uninformative (Table 1).

List of 45 morphological characters used in the cladistic analysis, with character states in brackets (note: NONA requires characters to start with 0 , rather than 1 ):

0 . Lateral cuticular windows on genital somite: present (0); absent (1).

1. Female genital somite and third urosomal somite: fused at least partly (0); clearly divided (1).

2. Anal operculum, additional dorsal row of spinules: absent (0); present (1).

3. Antennula, tube pore on first segment: absent $(0)$; present (1).

4. Antenna, number of elements on exopod: three (0); reduced (1).

5. Mandibula, inner basal seta: present (0); absent (1).

6. Mandibula, number of apical setae on endopod: five (0); reduced (1).

7. Maxillula, number of setae on endopod: two (0); reduced (1).

8. Maxilla, proximal endite on syncoxa: present (0); absent (1).

9. Maxilliped, seta on syncoxa: present (0); absent (1).

10. First leg, third exopodal segment, proximal outer spine: present (0); absent (1).

11. First leg, first endopodal segment, inner seta: present (0); absent (1).

12. First leg, second endopodal segment, inner seta: present (0); absent (1).

13. Second and fourth legs, first exopodal segment, inner seta: present (0); absent (1).

14. Second leg, third exopodal segment, proximal outer spine: present (0); absent (1).

15. Second leg, third exopodal segment, proximal inner seta: present (0); absent (1).

16. Second leg, third exopodal segment, distal inner seta: present (0); absent (1).

17. Second leg, first endopodal segment, inner seta: present (0); absent (1).

18. Second leg, second endopodal segment, inner seta: present (0); absent (1).

19. Second leg, third endopodal segment, distal inner seta: present (0); absent (1).

20. Second leg, third endopodal segment, apical inner seta: present (0); absent (1).

21. Second leg, third endopodal segment, apical outer seta: present (0); absent (1).

22. Third leg, third exopodal segment, proximal outer spine: present (0); absent (1).

23. Third leg, third exopodal segment, middle inner seta: present (0); absent (1).

24. Third leg, third exopodal segment, distal inner seta: present (0); absent (1).

25. Third leg, first endopodal segment, inner seta: present (0); absent (1). 
Table 1. Character matrix for the phylogenetic analysis of species in the genus Nitocrellopsis Galassi, De Laurentiis \& DoleOlivier, 1999. Three outgroups are: Biameiropsis barrowensis Karanovic, 2006, Nitokra lacustris pacifica Yeatman, 1983, and Parapseudoleptomesochra tureei Karanovic, 2006. See text for more details.

\begin{tabular}{|c|c|c|c|c|c|c|c|c|c|c|c|c|c|c|c|c|c|c|c|c|c|c|c|c|c|c|c|c|c|c|c|c|c|c|c|c|c|c|c|c|c|c|c|c|c|}
\hline axon $\backslash$ Character & 0 & 1 & 2 & 3 & 4 & 5 & 6 & 7 & 8 & 9 & 10 & 1 & 2 & 3 & 4 & 5 & 6 & 7 & 8 & 9 & 20 & 1 & 2 & 3 & 4 & 5 & 6 & 7 & 8 & 9 & 30 & & & & & & 5 & 6 & & & 8 & 40 & 1 & 7 & 3 \\
\hline B. barrowensis & 1 & 0 & 0 & 0 & 0 & 0 & 1 & 0 & 0 & 0 & 0 & 0 & 0 & 0 & 0 & 0 & 0 & 0 & 0 & 0 & 0 & 0 & 0 & 0 & 0 & 0 & 0 & 0 & 0 & 0 & $\overline{0}$ & 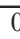 & & & & & 0 & $\overline{0}$ & 0 & & 0 & 0 & 0 & 0 & 0 \\
\hline V. l. pacifica & 1 & 0 & 0 & 0 & 0 & 0 & 1 & 0 & 0 & 0 & 0 & 0 & 0 & 1 & 0 & 0 & 0 & 1 & 0 & 0 & 0 & 1 & 0 & 0 & 0 & 1 & 0 & 0 & 0 & 0 & 0 & & & & & & 0 & 0 & & & 1 & 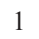 & & & 0 \\
\hline P. tureei & 0 & 0 & 0 & 1 & 0 & 1 & 0 & 0 & 0 & 0 & 0 & 0 & 1 & 1 & 0 & 1 & 0 & 0 & 0 & 0 & 0 & 1 & 1 & 1 & 0 & 0 & 0 & 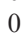 & 0 & 1 & 0 & & & & & & 0 & 0 & & & 1 & 0 & & 0 & 0 \\
\hline N. ahaggarensis & 1 & 0 & 0 & 0 & 0 & 1 & 0 & 0 & 0 & 0 & 1 & 1 & 1 & 1 & 1 & 1 & 1 & 1 & 1 & 1 & 0 & 1 & 1 & 1 & 1 & 1 & 1 & 1 & 1 & 1 & 1 & & & & ) & & 1 & 1 & 0 & & 1 & 0 & 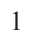 & 0 & 0 \\
\hline N. elegans & 1 & 0 & 0 & - & 0 & - & - & - & - & - & 0 & 0 & 1 & 1 & 1 & 1 & 0 & 0 & 0 & 1 & 0 & 1 & 1 & 1 & 0 & 0 & 0 & 1 & 0 & 1 & 1 & & & & & & 1 & 1 & U & & 1 & 1 & & 0 & 1 \\
\hline N. halsei & 1 & 1 & 1 & 1 & 0 & 1 & 1 & 0 & 1 & 0 & 0 & 0 & 1 & 1 & 0 & 1 & 1 & 0 & 0 & 1 & 0 & 1 & 1 & 1 & 1 & 0 & 0 & 1 & 1 & 1 & 1 & & & & ) & ) & 1 & * & 0 & 1 & 0 & 0 & 0 & 0 & 0 \\
\hline N. hellenica & 1 & 1 & 1 & 0 & 0 & 1 & 0 & 0 & 1 & 1 & 1 & 0 & 1 & 1 & 1 & 1 & 1 & 1 & 1 & 1 & 1 & 1 & 1 & 1 & 1 & 1 & 1 & 1 & 1 & 1 & & & & & ) & & 1 & 1 & 1 & & 1 & 0 & & 0 & 1 \\
\hline N. hippocratis & 1 & 1 & 1 & 0 & 0 & 1 & 1 & 1 & 1 & 1 & 1 & 0 & 1 & 1 & 1 & 1 & 1 & 1 & 1 & 1 & 1 & 1 & 1 & 1 & 1 & 1 & 1 & 1 & 1 & 1 & 1 & & & & ) & & 1 & 1 & 1 & 1 & 1 & 0 & 1 & ) & 1 \\
\hline N. ioneli & 1 & 0 & 0 & 0 & 0 & 1 & 0 & 0 & 0 & 0 & 1 & 1 & 1 & 1 & 1 & 1 & 1 & 1 & 1 & 1 & 0 & 1 & 1 & 1 & 1 & 1 & 1 & 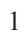 & 1 & & & & & & ) & & 1 & 1 & 0 & & 1 & 0 & 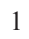 & 0 & 0 \\
\hline N. operculata & 0 & 0 & 0 & 1 & 1 & 1 & 0 & 1 & 1 & 0 & 0 & 0 & 1 & 1 & 0 & 1 & 0 & 0 & 0 & 0 & 0 & 1 & 1 & 1 & 0 & 0 & 0 & & 0 & I & & & & & ) & & 1 & 0 & 0 & & 1 & 1 & & 0 & 1 \\
\hline N. petkovskii & 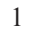 & . & 0 & - & 0 & 1 & 0 & 1 & 1 & 1 & 1 & 0 & 1 & 1 & 1 & 1 & 0 & 1 & 1 & 1 & 0 & 1 & 1 & 1 & 0 & 1 & 1 & & 1 & & & & & & & & 1 & 1 & 0 & & 1 & 0 & & 1 & 1 \\
\hline N. pinderi & 1 & 1 & 1 & 1 & 0 & 1 & 0 & 0 & 1 & 0 & 0 & 0 & 1 & 1 & 0 & 1 & 1 & 0 & 0 & 1 & 0 & 1 & 1 & 1 & 1 & 0 & 0 & & 1 & & & & & & & & 1 & 0 & 0 & & 0 & 0 & ) & 0 & 0 \\
\hline N. rouchi & 1 & 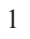 & 1 & 1 & 0 & 0 & 0 & 1 & 0 & 0 & 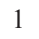 & 1 & 1 & 1 & 1 & 1 & 1 & 1 & 1 & 1 & 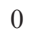 & & 1 & 1 & 1 & 1 & 1 & & 1 & & & & & & & & 1 & 1 & 0 & & 1 & 0 & & 0 & \\
\hline N. texana & 1 & 0 & 0 & 0 & 0 & 1 & 0 & 1 & 0 & 0 & 1 & 0 & 1 & 1 & 1 & 1 & 1 & 0 & 0 & 1 & 0 & 1 & 1 & 1 & 1 & 0 & 0 & & 1 & & & & & & & & 1 & 1 & & & 1 & & 1 & 1 & \\
\hline
\end{tabular}

26. Third leg, second endopodal segment, inner seta: present (0); absent (1).

27. Third leg, third endopodal segment, middle inner seta: present (0); absent (1).

28. Third leg, third endopodal segment, distal inner seta: present (0); absent (1).

29. Third leg, third endopodal segment, outer apical seta: present (0); absent (1).

30. Fourth leg, endopod: 3-segmented (0), 2-segmented (1).

31. Fourth leg, third exopodal segment, proximal outer spine: present (0); absent (1).

32. Fourth leg, third exopodal segment, proximal inner seta: present (0); absent (1).

33. Fourth leg, third exopodal segment, distal inner seta: present (0); absent (1).

34. Fourth leg, first endopodal segment, inner seta: present (0); absent (1).

35. Fourth leg, ultimate endopodal segment, proximal inner seta: present (0); absent (1).

36. Fourth leg, ultimate endopodal segment, distal inner seta: present (0); absent (1).

37. Fourth leg, ultimate endopodal segment, inner apical seta: present (0); absent (1).

38. Fourth leg, ultimate endopodal segment, outer apical seta: present (0); absent (1).

39. Male fifth leg endopod, number of elements: 3 or more (0); 2 or less (1).

40. Male fifth leg endopod, number of elements: 2 or more (0); 1 or none (1).

41. Female fifth leg endopod, first element from inner side: present (0); absent (1).

42. Female fifth leg endopod, second element from inner side: present (0); absent (1).

43. Female fifth leg endopod, fifth element from inner side: present (0); absent (1).

44. Female fifth leg exopod, fifth seta from inner side: present (0); absent (1).

\section{Systematics}

Class Copepoda H. Milne Edwards, 1840

Order Harpacticoida Dana, 1846

Family Ameiridae Monard, 1927

Genus Nitocrellopsis Galassi, De Laurentiis \& DoleOlivier, 1999.

\section{Nitocrellopsis halsei sp. nov. (Figs. 1-4 and 11)}

Type material. Holotype, adult female dissected on one slide (WAM C37315); allotype, adult male dissected on one slide (WAM C37316); paratypes, two adult males dissected on one slide (WAM C37317), two adult females dissected on one slide (WAM C37318), one adult male + 18 adult females + five copepodids in one vial in $70 \%$ alcohol (WAM C37319), and one adult male + seven adult females on one SEM stub (WAM C37319A); Australia, Western Australia, Yilgarn region, Regis, bore MNRB008, 5 June 2007, leg. Jim Cocking and Mike Scanlon (Bennelongia Pty Ltd), 2730'52.9"S $122^{\circ} 21^{\prime} 32.9^{\prime \prime} \mathrm{E}$.

Description. Female (holotype). Total body length, measured from tip of rostrum to posterior margin of caudal rami (excluding appendages and caudal setae), $0.501 \mathrm{~mm}$. Preserved specimen colourless. Nauplius eye absent. Prosome comprising cephalothorax with completely fused first pedigerous somite, and three free pedigerous somites; urosome six-segmented, comprising fifth pedigerous somite, genital somite and four abdominal somites. Sclerotized joint (almost as pseudosomite) present between prosome and urosome. Habitus (Fig. 1A) cylindrical, very slender, without distinct demarcation between prosome and urosome; prosome/urosome ratio 0.93 and greatest width at posterior end of cephalothorax. Body length/width ratio about 5.2; cephalothorax 1.2 times as wide as genital somite. Free pedigerous somites without 
pronounced lateral or dorsal expansions. Integument not very strongly chitinized and without cuticular windows. Rostrum small, membranous, linguiform, reaching just beyond half length of first antennular segment, about 2.5 times as long as wide and not demarcated at base; ornamented with two dorsal sensilla.

Cephalothorax (Fig. 1A) almost trapezoidal in dorsal view, about 1.2 times as long as wide; represents $23 \%$ of total body length. Surface of cephalic shield ornameted just with few large sensilla, as well as tergites of three free pedigerous somites. Fourth pedigerous somite (third free) with two very large dorsolateral cuticular pores (Fig. 1A). Hyaline fringes of all prosomites narrow and smooth. Fifth pedigerous (first urosomal) somite ornamented with six dorsal and four lateral sensilla (two on each side), as well as with two lateral pores (one on each side); hyaline fringe finely serrated dorsolaterally.

Genital somite (Fig. 1B) completely free, very short, with smooth hyaline fringe ventrally and finely serrated dorsally and laterally. Ornamentation consists of four dorsal and four lateral (two on each side) sensilla, short arched ventrolateral row of small spinules on each side near ventolateral sensillum, and one small cuticular pore at middle of this row, somewhat anteriorly. Female genital complex with single ovoid copulatory pore near posterior magin, weakly sclerotized, narrow copulatory duct and two small, ovoid seminal receptacles. Single large genital aperture covered by fused reduced sixth legs, represents $58 \%$ of somite width. Third and fourth urosomites ornamented very similarly, with posterior interrupted row of spinules ventrolaterally, along with eight large sensilla (two dorsal, two ventral and two lateral on each side) and six (third urosomite) or four (fourth urosomite) ventrolateral cuticular pores; hyaline fringe finely serrated both dorsally and ventrally; ventral spinules between ventral sensilla smaller than others. Preanal somite ornamented with posterior uninterrupted row of spinules, additional row of minute spinules ventrally, and two lateral cuticular pores (one on each side); hyaline fringe also finely serrated both dorsally and ventrally. Anal somite (Figs. 1B and 2A) ornamented with pair of large dorsal sensilla, two large cuticular pores next to them, six ventral and two lateral smaller pores, and transverse row of large spinules along posterior margin, dorsal ones longer than ventral. Anal operculum convex, not reaching posterior end of anal somite, represents $44 \%$ of somite's width, ornamented with 12 strong spinules near posterior margin and additional row of smaller spinules anteriorly. Anal sinus without ornamentation. All ursomites additionally ornamented with irregularly placed short rows of minute spinules, most of which hardly visible.

Caudal rami (Figs. 1B and 2A) small, much shorter than anal somite, about 1.5 times as long as wide (ventral view), slightly divergent, with space between them more than one ramus width; armed with seven armature elements (three lateral, one dorsal and three apical). Ornamentation consists of three spinules at base of distal lateral seta, three spinules at base of dorsal seta, posterior row of three or four spinules ventrally and one dorsal, two lateral, and three ventral pores. Dorsal seta relatively long, inserted near posterior margin, about 1.8 times as long as caudal ramus, triarticulate at base (i.e. inserted on two pseudojoints). Proximal lateral seta about as long as dorsal seta, arising dorsolaterally at $2 / 3$ of ramus length. Distal lateral seta slightly longer than dorsal or proximal lateral, arising laterally at $3 / 4$ of ramus length. Dorsal and all three lateral setae smooth. Inner apical seta also smooth, almost half as long as distal lateral seta and about 0.8 times as long as ramus. Middle apical seta strongest, with breaking plane, pinnate at distal end, about twice as long as outer apical seta and 0.4 times as long as total body length. Outer apical seta also with breaking plane and pinnate at distal end.

Antennula (Fig. 2B) eight-segmented, joined to cephalotholax with small triangular pseudosegment laterally, approximately 1.2 times as long as cephalothorax. Long aesthetasc on fourth segment fused basally with adjacent large seta and reaches beyond tip of appendage for length of last three segments; slender apical aesthetasc on eight segment fused basally with two apical setae, forming apical acrothek. Setal formula: 1.9.8.3.2.3.4.7. Only seta on first segment unipinnate, all other setae smooth. Two lateral setae on seventh segment and four lateral setae on eighth segment biarticulate at base. All other setae setae uniarticulate and without breaking planes. First segment ornamented with cuticular tube pore on anterior surface and diagonal row of spinules along inner margin; other segments without any ornamentation. Length ratio of antennular segments, from proximal end, $1: 2.4: 1.3: 1.8$ : $0.9: 1.2: 0.8: 1.4$.

Antenna (Fig. 2C) short, composed of coxa, basis, twosegmented endopod and one-segmented exopod. Coxa very short, unarmed and unornamented. Basis only slightly longer than wide, more than three times as long as coxa, ornamented with row of spinules along inner margin, unarmed. First endopodal segment about 2.2 times as long as wide and 1.7 times as long as basis, unornamented and unarmed. Second endopodal segment 1.3 times as long as first endopodal segment, with two surface frills subdistally, armed laterally with two spines flanking thin seta; apical armature consisting of five geniculate setae, longest one fused basally to additional smaller seta, bearing proximal tuft of fine setules and bipinnate distally; ornamentation consists of long spinules along anterior surface. Exopod slightly shorter than basis, with very narrow basal part and somewhat wider distal part, unornamented, armed with three apical strong and pinnate setae.

Labrum (Fig. 1C) large compared with cephalothorax, trapezoidal, rigidly sclerotized, with relatively short and somewhat concave cutting edge, ornamented subapically with two rows of six or seven strong spinules and apically with minute spinules. Two ovoid fields of gustatory papillae on dorsal (posterior) surface, between rows of strong spinules and strongly chitinized medial horseshoe.

Paragnaths ellipsoid, about twice as long as wide, with group of spinules of different length apically, few spinules laterally, as well as group of four large spinules on proximal inner part of each lobe, continuing with row of much 
smaller spinules. Not mounted in satisfactory position to allow drawing.

Mandibula (Fig. 1D) with narrow cutting edge on elongated coxa, armed with three coarser teeth at ventral half, finer teeth at dorsal half (one tooth at middle stronger and longer than others) and one dorsal unipinnate seta. Palp uniramous, comprising basis and one-segmented endopod. Basis with inflated distal part, about 1.4 times as long as wide, unarmed, ornamented with three strong spinules on inner margin. Endopod slender and unornamented, about 0.7 times as long as basis and twice as long as wide; armed with four slender and smooth setae apically.

Maxillula (Fig. 2D) with large praecoxa, arthrite rectangular, ornamented with short transverse row of spinules on anterior surface; armed with two anterior surface setae, three lateral and four apical elements (probably three spines and one seta). Coxal endite much shorter than praecoxal arthrite, armed with one curved and stout, unipinnate seta and two smooth, slender setae. Basis slightly shorter than coxal endite, armed with five smooth setae apically and subapically. Endopod represented by minute segment, armed with two apical smooth setae of about same length.

Maxilla (Fig. 2E) with proximal endite of syncoxa completely reduced; distal endite well developed, highly mobile, armed with one curved pinnate spine and two smooth subequal setae apically, which somewhat longer than spine. Basis drawn out into long claw, with shorter spiniform and curved seta at base, ornamented with cuticular pore basally and minute spinules along convex margin. Endopod represented by minute segment, armed with two long and smooth, subequal apical setae.

Maxilliped (Fig. 1E) with short syncoxa, ornamented with two rows of minute spinules and armed with one unipinnate seta subapically. Basis about 2.5 times as long as wide and 1.5 times as long as syncoxa, ornamented with two spinules subapically and unarmed. Endopod represented by long curved claw, about as long as basis, ornamented with row of spinules along concave side distally, accompanied at base by thin smooth and short seta.

Swimming legs with three-segmented exopod and first three also with three segmented endopod (Figs. 2F, 2G and 3A). Endopod of fourth swimming leg two segmented (Fig. 3B). Armature formula of swimming legs as follows (for preultimate segments-inner/outer elements; for ultimate segments - inner/terminal/outer elements):

\begin{tabular}{lccccccc}
\hline & \multicolumn{3}{c}{ Exopod } & & \multicolumn{3}{c}{ Endopod } \\
\cline { 2 - 4 } \cline { 6 - 8 } Segments & 1 & 2 & 3 & & 1 & 2 & 3 \\
\hline First leg & $0 / 1$ & $1 / 1$ & $0 / 2 / 3$ & & $1 / 0$ & $0 / 0$ & $1 / 1 / 1$ \\
Second leg & $0 / 1$ & $1 / 1$ & $0 / 2 / 3$ & & $1 / 0$ & $1 / 0$ & $0 / 1 / 1$ \\
Third leg & $0 / 1$ & $1 / 1$ & $0 / 2 / 2$ & & $1 / 0$ & $1 / 0$ & $0 / 1 / 1$ \\
Fourth leg & $0 / 1$ & $1 / 1$ & $2 / 2 / 2$ & & $1 / 0$ & $1 / 1 / 1$ & - \\
\hline
\end{tabular}

Intercoxal sclerite of all swimming legs with concave distal margin; that of second leg (Fig. 2G) ornamented with two arched rows of spinules near distal margin, others without any surface ornamentation. Praecoxa with row of long spinules along outer posterior margin. Coxa of first swimming leg (Fig. 2F) ornamented with several rows of spinules of different size; coxae of other legs unornamented and all coxae unarmed. Basis ornamented with very long spinules on outer margin, armed with outer spine on first and second swimming legs and with outer smooth seta on third and fourth legs; basis of first leg with short and stout spine near inner distal corner and several spinules at its base, as well as additional row of spinules posteriorly between exopod and endopod and large pore basally. Exopods and endopods of all swimming legs ornamented with long spinules along outer margin and some segments also with spinules along inner and distal margin. First exopodal segment of all legs slightly shorter than second exopodal segment. First endopodal segment of first swimming leg (Fig. 2F) stout, about 2.6 times as long as wide, somewhat shorter than first two exopodal segments. Endopods of second and third swimming legs (Figs. 2G and $3 \mathrm{~A}$ ) reaching slightly beyond second exopodal segment in length; while endopod of fourth swimming leg (Fig. 3B) reaching middle of second exopodal segment. All setae on exopods and endopods strong and spiniform, except minute inner seta on third endopodal segment of first leg and apical endopodal seta in other legs, as well as inner apical seta on exopods of second, third and fourth legs.

Fifth leg (Fig. 3C) biramous, baseoendopods not fused. Baseoendopod with outer basal seta long and smooth, arising from long setophore. Endopodal lobe relatively wide, slightly convex, extending only to first $1 / 3$ of exopod in length, ornamented with large pore at middle and row of spinules along outer margin, armed with five stout, bipinnate setae, with length ratio (from inner side) $1: 1: 1.2: 2.9: 1.2$. Exopod ovoid, about 1.8 times as long as maximum width, ornamented with few slender spinules along inner margin and small pore at $2 / 3$ of its length, close to outer margin, armed with four setae; third seta from inner side pinnate and strong, other three setae smooth and slender. Length ratio of four exopodal setae, from inner side, $1: 0.8: 0.3: 0.7$.

Sixth legs (Fig. 1B) completely fusedtogether, indistinct, forming simple operculum covering single gonopore, without any ornamentation, each armed with outer short pinnate seta and even much shorter smooth inner spine.

Male (allotype). Body length, excluding caudal setae, $0.465 \mathrm{~mm}$. Habitus (Fig. 3E), ornamentation of prosomites, rostrum, colour and nauplius eye similar to female. Hyaline fringe of all prosomites smooth and large cuticular pores on third free prosomite also present. Prosome/ urosome ratio 0.88 , greatest width at posterior end of cephalothorax and first free prosomite, body length/width ratio about 4.9; cephalothorax 1.2 times as wide as genital somite.

Genital somite (Fig. 4A) twice as wide as long, with small and longitudinally positioned spermatophore (Fig. 3E) visible inside in the right half, which somewhat shorter than somite and twice as long as wide. Urosomites ornamentation similar to female, although posterior row of spinules not of smaller size ventrally on third and 


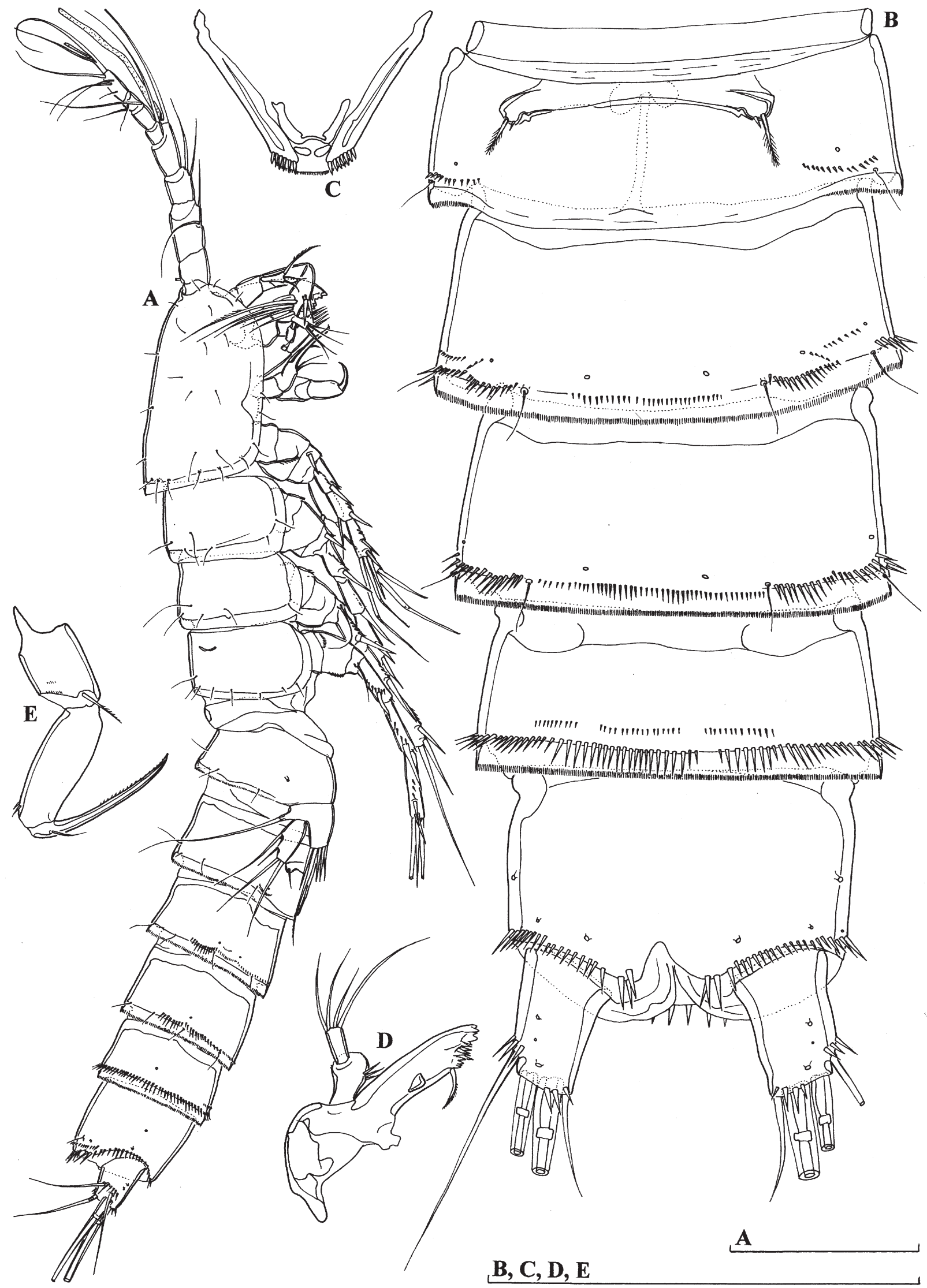

Fig. 1. Nitocrellopsis halsei sp. nov., holotype female: A-habitus, lateral view; B-abdomen, ventral view; C-labrum; $\mathrm{D}$ - mandibula; $\mathrm{E}$ - maxilliped. Scales $=0.1 \mathrm{~mm}$. 


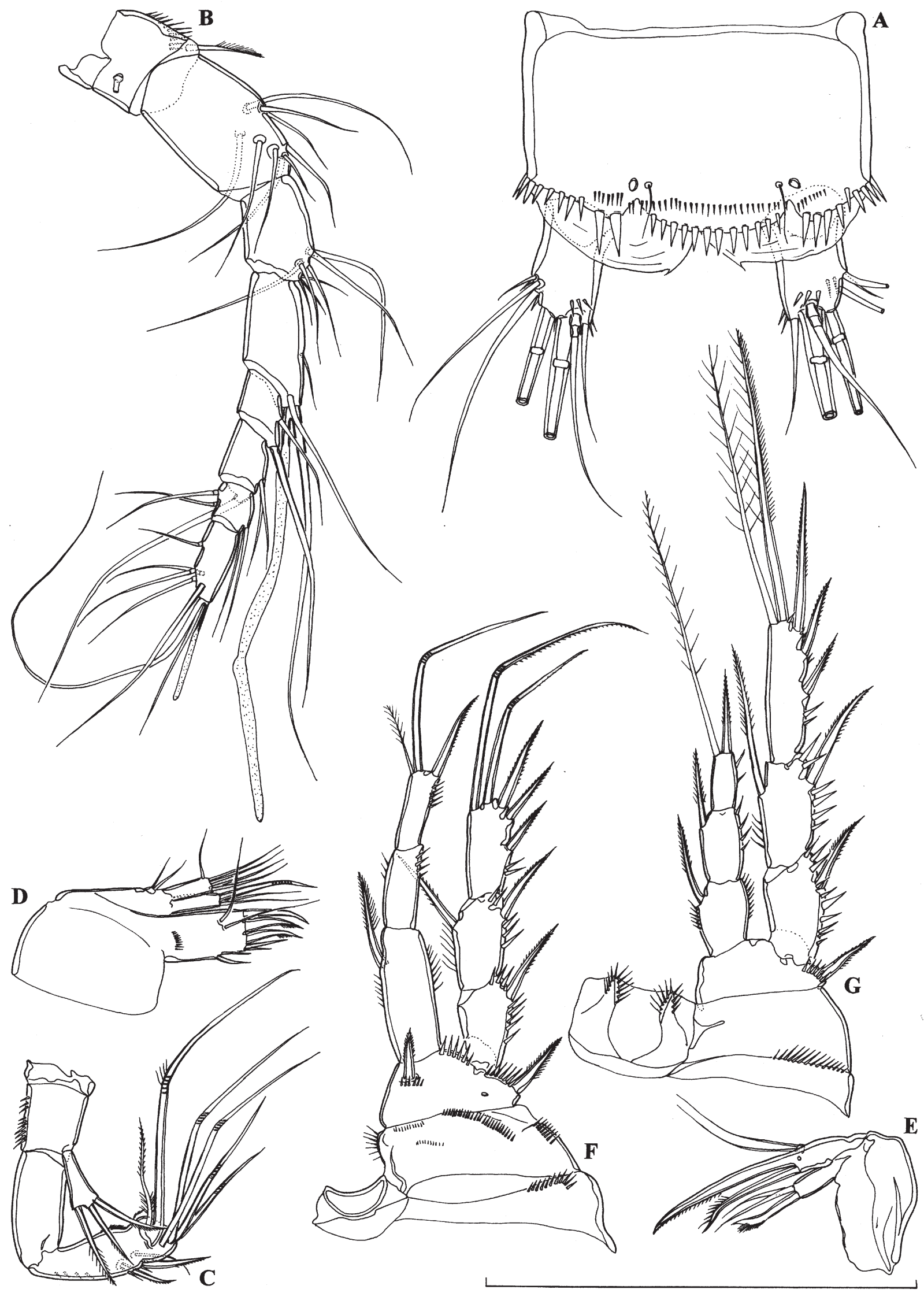

Fig. 2. Nitocrellopsis halsei sp. nov., holotype female: A - anal somite and caudal rami, dorsal view; B - antennula; C-antenna; $\mathrm{D}$ - maxillula; E - maxilla; F - first swimming leg; $\mathrm{G}$ - second swimming leg. Scale $=0.1 \mathrm{~mm}$. 


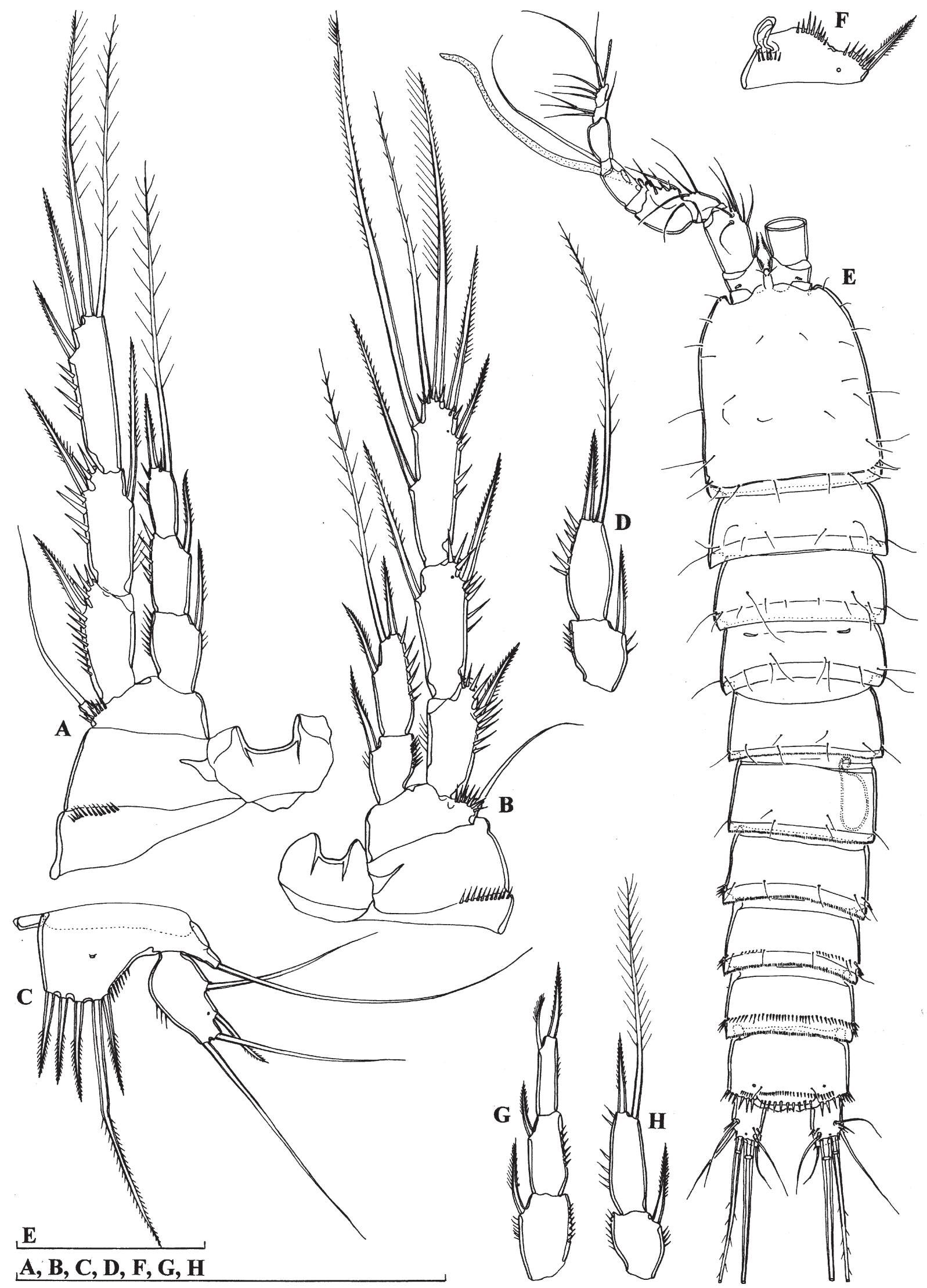

Fig. 3. Nitocrellopsis halsei sp. nov., A-C, holotype female; D, paratype female (0.587 mm long, WAM C37318); E-H, allotype male: A - third swimming leg; B - fourth swimming leg; C - fifth leg; D - endopod of fourth swimming leg; E - habitus, dorsal view; $\mathrm{F}$ - basis of first swimming leg; $\mathrm{G}$ - endopod of third swimming leg; $\mathrm{H}$ - endopod of fourth swimming leg. Scales $=0.1 \mathrm{~mm}$. 


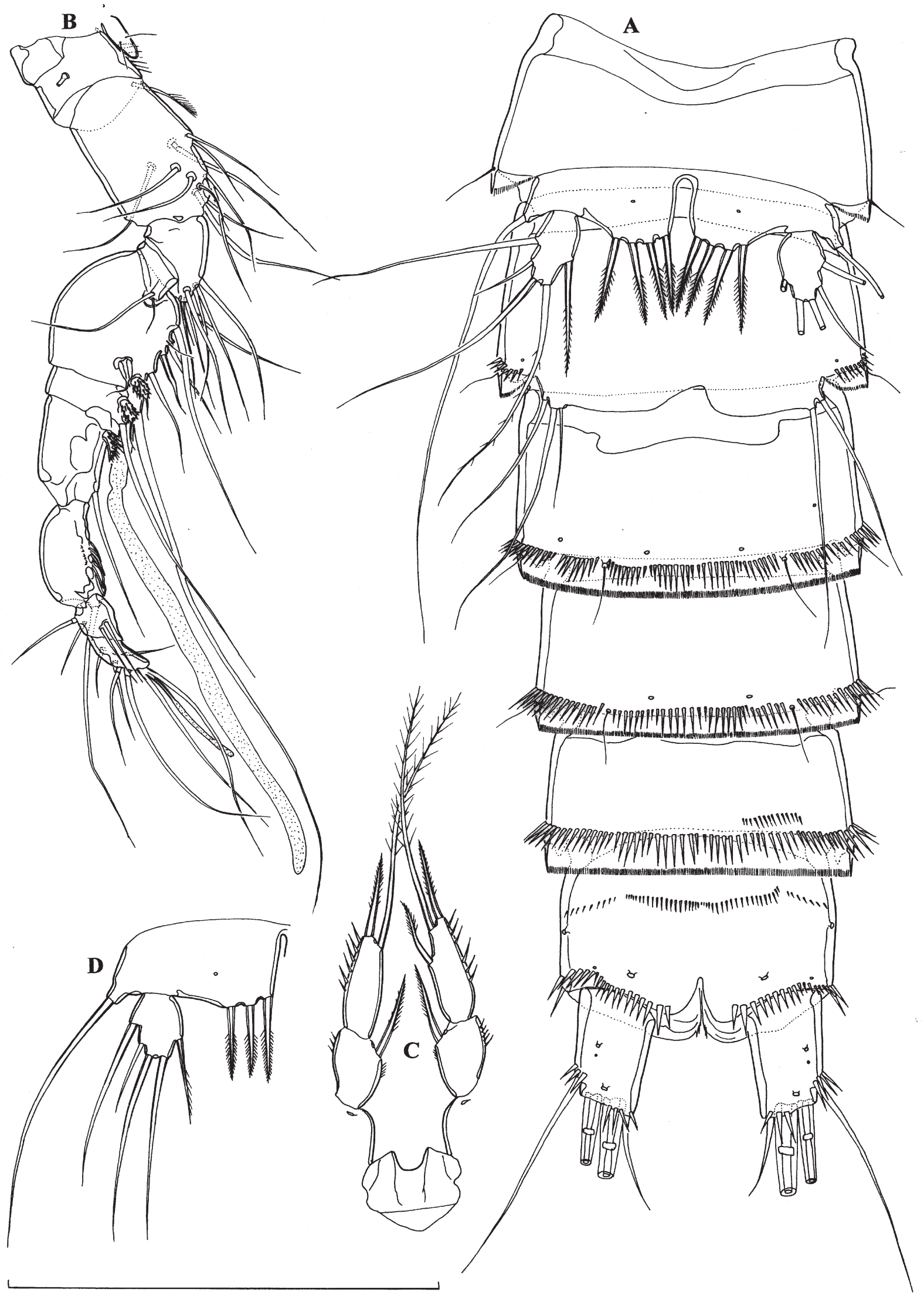

Fig. 4. Nitocrellopsis halsei sp. nov., A-B, allotype male; C, paratype male (0.493 mm long, WAM C37317); D, paratype male (0.473 mm, WAM C37317): A - urosome, ventral view; B - antennula and rostrum; C - endopods of left and right fourth swimming leg; D - fifth leg. Scale $=0.1 \mathrm{~mm}$. 
fourth somite. Anal somite with additional row of smaller spinules ventrally at anterior half (Fig. 4A). Anal operculum with 10 large posterior spinules.

Caudal rami (Fig. 4A) with the same armature and ornamentation as in female, although slightly more cylindrical.

Antennula (Fig. 4B) long and slender, ten-segmented, strongly geniculate, with geniculation between seventh and eighth segment; ornamented with row of spinules and cuticular tube pore on first segment. Eight segment with inner margin strongly chitinized, with several smaller and three larger spine-like structures. Very long aesthetasc on apical acrothek of fifth segment (homologueue to aesthetasc on fourth segment in female); very slender aesthetasc on tenth segment apically also fused to two apical setae. First two and last two segments similar to female, although last segment somewhat shorter. Setal formula: 1.11.8.2.8.2.2.1.4.7. Majority of setae smooth and slender; seta on first segment pinnate; two setae on fifth, one on sixth and one on seventh segment very short and spiniform basally and covered with several rows of strong spinules, except proximal one on fifth segment, which bears no spinules but has finally serrated lateral sides; all these setae distally slender and smooth and with pore on tip. Only three lateral setae on tenth segment and two setae on ninth segment barticulate basally. No setae with breaking plane.

Antenna, labrum, paragnaths, mandibula, maxillula, maxilla, maxilliped and second swimming leg similar to female.

First swimming leg (Fig. 3F) with spatula-shaped and smooth modified inner spine on basis, 0.8 times as long as basis and directed outwards.

Third swimming leg (Fig. 3G) with apical seta on third endopodal segment unipinnate, shorter than spine and inserted more subapically; other details similar to female.

Fourth swimming leg (Fig. 3H) with only two armature elements on second endopodal segment, inner seta missing.

Fifth legs (Fig. 4A) with baseoenopods fused only basally, forming a very narrow bridge. Baseoendopod with outer basal seta very long, smooth, arising from long setophore and reaching middle of fourth urosomal segment. Endopodal lobe broad, concave, not extending to middle of exopod, unornamented (except for medial cuticular pore) and armed with four stout, bipinnate spines of subequal length, as long as baseoendopod. Exopod without ornamentation along inner margin, but with additional spiniform inner seta, about 1.5 times as long as exopod.

Sixth legs (Fig. 4A) completely fused basally to each other and to somite, armed with two or three smooth setae; innermost seta absent on left leg; length ratio of setae, from inner side, $1: 2.4: 1.7$.

Variability. Body length of females ranges from $0.501 \mathrm{~mm}$ to $0.625 \mathrm{~mm}(0.579 \mathrm{~mm}$ average; $n=11)$, while in males it ranges from $0.468 \mathrm{~mm}$ to $0.546 \mathrm{~mm}(0.375 \mathrm{~mm}$ average; $n=5)$. One paratype female has only two armature elements on the second endopodal segment of both fourth legs (Fig. 3D), with the inner seta missing, while another paratype female was observed with the left fourth leg with two armature elements on that segment and the right fourth leg as in the holotype. The former paratype female also has 11 large spinules on the anal operculum, while the latter has 12, just like the holotype. Similar variability in the armature of the second endopodal segment of the fourth leg was observed among paratype males (Fig. 4C). Habitus shape and proportions vary remarkably little among examined specimens (Fig. 11A), but the pattern, size, and exact position of minute spinules on urosomites vary remarkably (Figs. 11B and 11C), and even the position of large sensilla on cephalothorax is not always exactly the same (Fig. 11D). One paratype female even lacks additional row of spinules on the anal somite (Fig. 11B), but that is a rare exception. All examined specimens have tubular pores on the first antennular segment (Fig. 11E) and their structure can nicely be examined with a scanning electron microscope (Fig. 11F). One paratype female has somewhat shorter middle seta on the antennal exopod (Fig. 11G). Allotype male shows asymmetry in the ornamentation of the preanal somite, as well as in the armature of the third exopodal segment of the third swimming leg (with only two outer spines on the right leg and three spine on the left one) and the armature of the sixth leg, with two setae on the left leg and three on the right (Fig. 4A). One paratype male has only three spines on the fifth leg baseoednopod, as well as a somewhat shorter exopod (Fig. 4D). Another paratype male was observed with this condition and with only two setae on both sixth legs. The fine structure of the spiniform antennular elements can only be observed with a scanning electron microscope (Fig. 11H), especially those fine serrations on the proximal part of the naked spine and the pore on tip of the distal slender part of all four transformed elements.

Etymology. The new species is named in honour of Dr Stuart Halse, the director of the consulting agency Bennelongia, who kindly sent this material for examination. The name is a noun in the genitive singular.

Remarks. Nitocrellopsis halsei sp. nov. is most closely related to $N$. pinderi sp. nov. (see below) and the two can be considered as sister species. They share the same armature formula of all swimming legs and the fifth leg in the female, as well as very similar mouth appendages morphology. Both also have a completely free genital somite in the female, as well as a remarkably similar fine ornamentation of body somites. There is no chance that all these characters could have evolved convergently and numerous similarities in microcharacters especially point to their probable sister species relationship.

Main differences between $H$. halsei and $N$. pinderi involve body size and habitus appearance (latter being a significantly larger and more robust species), as well as the caudal rami shape and size (they are much smaller in proportion to the anal somite in the former species, as well as less elongated from lateral view (Figs. 1A, 1B, 2A, 5A, 5B and 6A)). Additionally, N. halsei can be distinguished from $N$. pinderi by the presence of large lateral pores on fourth pedigerous somite (Figs. 1A and 5A), less spinules 
on the anal operculum, only four setae on the mandibular endopod (Figs. 1D and 7A), and much more elongated exopod of the fifth leg both in females (Figs. 3C and 5E) and males (Figs. 4A and $7 \mathrm{H}$ ).

Morphology would suggest that these two sister species from the Yilgarn region in Western Australia have no close relatives among other representatives of the genus Nitocrellopsis or any other freshwater ameirid, but more on this is elaborated in the discussion section below. They differ remarkably from the below described Nitocrellopsis operculata sp. nov., which comes from the neighbouring Pilbara region in Western Australia. Some of the main differences include the absence of the cuticular windows and a different pattern of somite ornamentation, completely free genital somite in the female, different armature of the second, third, fourth and fifth legs, as well as the armature of the antennal exopod (which has only two elements in $N$. operculata).

\section{Nitocrellopsis pinderi sp. nov. (Figs. 5-7)}

Type material. Holotype, adult female dissected on one slide (WAM C37320); Australia, Western Australia, Yilgarn region, Regis, bore MNRB009, 5 June 2007, leg. Jim Cocking and Mike Scanlon (Bennelongia Pty Ltd), $27^{\circ} 30^{\prime} 53.3^{\prime \prime S} 122^{\circ} 21^{\prime} 37.3^{\prime \prime} \mathrm{E}$.

Other material examined. One adult male dissected on one slide (WAM C37321); Australia, Western Australia, Yilgarn region, Regis, bore MNRB15, 4 September 2007, leg. Jim Cocking and Mike Scanlon (Bennelongia Pty Ltd), 27²8'50.6"S 122 20'28.3"E.

Description. Female (holotype). Total body length, measured from tip of rostrum to posterior margin of caudal rami (excluding caudal setae), $0.455 \mathrm{~mm}$. Preserved specimen colourless. Nauplius eye absent. Musculature strongly contracted and anterior parts of many somites infolded into posterior part of previous somite, resulting in unnaturally short body. Prosome and urosome articulation same as in previous species. Sclerotized joint (almost as pseudosomite) present between prosome and urosome. Habitus (Fig. 5A) cylindrical but very robust, without distinct demarcation between prosome and urosome; prosome/urosome ratio 1.3 and greatest width at posterior end of cephalothorax. Body length/width ratio about 4.1; cephalothorax 1.3 times as wide as genital somite. Free pedigerous somites without pronounced lateral or dorsal expansions. Integument not very strongly chitinized and no cuticular windows or minute cuticular pits present. Rostrum (Fig. 6B) small, membranous, linguiform, reaching just beyond half length of first antennular segment, about 1.6 times as long as wide and not demarcated at base; ornamented with two large dorsal sensilla.

Cephalothorax (Fig. 5A) about 1.2 times as long as wide, represents $35 \%$ of total body length. Surface of cephalic shield ornameted with many large sensilla, as well as tergites of three free pedigerous somites. Third free pedigerous somite without large dorsolateral cuticular pores, which present in previous species. Hyaline fringes of all prosomites smooth. Fifth pedigerous (first urosomal) somite (Fig. 5A) ornamented with two dorsal and two lateral sensilla (one on each side), as well as with two lateral pores (one on each side); hyaline fringe finely serrated dorsolaterally.

Genital somite (Fig. 6A) completely free, very short, with smooth hyaline fringe ventrally and finely serrated dorsally and laterally. Ornamentation of urosomites very similar to previous species, except additional row of small spinules missing from preanal somite (Fig. 6A). Female genital complex also very similar to previous species. Anal somite (Figs. 5B and 6A) ornamented with pair of large dorsal sensilla, two small cuticular pores next to them, two ventral and two lateral smaller pores (one on each side), and transverse row of large spinules along posterior margin, dorsal ones not longer than ventral. Anal operculum convex, not reaching posterior end of anal somite, represents $39 \%$ of somite's width, ornamented with 19 strong spinules near posterior margin and additional row of minute spinules anteriorly. Anal sinus without ornamentation. Additional minute spinules present on all urosomal somite, as in previous species.

Caudal rami (Figs. 5A, 5B and 6A) large and long (especially from lateral view), about as long as anal somite and much wider at basal part than in previous species, 1.3 times as long as greatest width (ventral view), slightly divergent, with space between them more than one ramus width; armature and ornamentation same as in previous species. Prncipal apical setae fused basally on right ramus, free on left.

Antennula (Fig. 5C) eight-segmented, joined to cephalothorax with small triangular pseudosegment laterally, approximately 1.4 times as long as cephalothorax. Long aesthetasc on fourth segment fused basally with adjacent large seta and reaches beyond tip of appendage for length of last two segments; slender and much smaller aesthetasc apically on eighth segment fused basally with two apical setae, forming apical acrothek. Setal formula and ornamentation same as in previous species. First segment also ornamented with cuticular tube pore on anterior surface and diagonal row of spinules on inner margin.

Antenna (Fig. 2C) very similar to previous species. Exopod shorter than basis, with very narrow basal part and somewhat wider distal part, unornamented, 2.2 times as long as greatest width, armed with three apical strong and pinnate setae; innermost seta longest and bipinnate, middle seta shortest and unipinnate, outermost seta also unipinnate, but with additional single long spinule near tip.

Labrum (Fig. 6C) large compared to cephalothorax, trapezoidal, rigidly sclerotized, with relatively short and somewhat concave cutting edge, ornamented subapically with two rows of six strong spinules and apically with minute spinules. Two ovoid fields of gustatory papillae on dorsal (posterior) surface, between rows of strong spinules and strongly chitinized medial horseshoe.

Paragnaths (Fig. 6D) ellipsoid, about 1.5 times as long as wide, with group of spinules of different length apically, four spinules laterally, as well as group of four large 
spinules on proximal inner part of each lobe, continuing with row of much smaller spinules.

Mandibula (Fig. 7A) with coxa very similar to previous species. Basis curved, about 1.5 times as long as wide, unarmed, ornamented with five strong spinules on inner (convex) margin. Endopod slender and unornamented, nearly as long as basis and 2.5 times as long as wide; armed with five slender and smooth setae apically.

Maxillula (Fig. 6F) with large praecoxa, arthrite rectangular, ornamented with short transverse row of spinules on anterior surface; armed with two anterior surface setae, four lateral and five apical elements (three spines and two setae). Coxal endite much shorter than praecoxal arthrite, armed with one curved and stout, unipinnate seta and two smooth, slender setae. Basis about as long as coxal endite, armed with five smooth setae apically and subapically. Endopod represented by minute segment, armed with two apical smooth setae (outer seta twice as long as inner one).

Maxilla (Fig. 6E) with proximal endite of syncoxa completely reduced; distal endite well developed, highly mobile, armed with one curved pinnate spine and two smooth subequal setae apically, which 1.8 times as long as spine. Basis drawn out into long claw, with shorter spiniform and curved seta at base, ornamented with cuticular pore basally and minute spinules along convex margin. Endopod represented by minute segment, armed with two very long and smooth, subequal apical setae.

Maxilliped same as in previous species.

Swimming legs segmentation and armature exactly same as in previous species (Figs. 6G, 6H, 7B and 7C). Third exopodal segments of second (Fig. 6G) and third (Fig. 6H) legs somewhat less slender. First endopodal segment of third swimming leg (Fig. 7B) somewhat shorter, when compared to two other segments, than in previous species. Second endopodal segment of fourth swimming leg (Fig. 7C) slightly longer and with subdivision membrane on outer margin, marking original ancestral segmentation (probably an atavism). Intercoxal sclerites of all swimming legs with concave distal margin and that of second leg ornamented with two arched rows of spinules near distal margin.

Fifth leg (Fig. 5E) biramous, baseoendopods not fused. Baseoendopod with outer basal seta long and smooth, arising from long setophore. Endopodal lobe relatively wide, slightly convex, extending only to first $1 / 3$ of exopod in length, ornamented only with small pore at middle, armed with five stout, bipinnate setae, with length ratio (from inner side) $1: 1: 1: 2.8: 1$. Exopod nearly round, about 1.3 times as long as maximum width, ornamented with strong spinules along inner margin and small pore at $2 / 3$ of its length, close to outer margin, armed with four setae; third seta from inner side pinnate and shortest, other three setae smooth and slender. Length ratio of four exopodal setae, from inner side, $1: 0.8: 0.4: 0.6$.

Sixth legs (Fig. 6A) completely fused, indistinct, forming simple operculum covering single gonopore, without any ornamentation, each armed with outer short pinnate seta and even much shorter smooth inner spine; another minute spine completely fused to leg and only visible as innermost tiny spiniform process.

Male (WAM C37321). Body length, excluding caudal setae, $0.693 \mathrm{~mm}$. Habitus, ornamentation of prosomites, rostrum, colour and nauplius eye similar to female. Hyaline fringe of all prosomites smooth and large cuticular pores on third free prosomite also absent.

Genital somite twice as wide as long, with small and longitudinally positioned spermatophore visible inside in the right half, somewhat shorter than somite. Urosomites ornamentation very similar to female. Anal operculum with 20 large posterior spinules.

Caudal rami large, twice as long as wide from ventral view, armature and ornamentation as in female.

Antennula (Fig. 7D) long and slender, ten-segmented, strongly geniculate, with geniculation between seventh and eighth segment; ornamented with row of spinules and cuticular tube pore on first segment. Eight segment with inner margin strongly chitinized, with several smaller and three larger spine-like structures, also with small cuticular pore. One very long aesthetasc on apical acrothek of fifth segment and one slender aesthetasc on tenth segment apically, fused to two apical setae. Armature very similar to previous species.

Antenna, labrum, paragnaths, mandibula, maxillula, maxilla, maxilliped and second swimming leg similar to female.

First swimming leg (Fig. 7E) with spatula-shaped and smooth modified inner spine on basis, 0.8 times as long as basis and directed outwards, somewhat more slender and less curved than in previous species.

Third swimming leg (Fig. 7F) with apical seta on third endopodal segment unipinnate, shorter than spine and inserted more subapically; other details similar to female.

Fourth swimming leg (Fig. 7G) with slightly shorter second endopodal segment and without subdivision suture on outer margin; armature same as in female.

Fifth legs (Fig. 7H) with baseoenopods fused basally, forming a narrow bridge. Baseoendopod with outer basal seta very long, smooth, arising from long setophore. Endopodal lobe broad, concave, not extending to middle of exopod, unornamented (except for medial cuticular pore) and armed with four stout, bipinnate spines of subequal length, as long as baseoendopod. Exopod also without ornamentation, armed as in previous species with additional spiniform inner seta, about 1.6 times as long as exopod.

Sixth legs (Fig. 7I) not fused basally to each other and also distinct from somite, armed with two smooth setae, inner seta 1.2 times as long as outer one.

Variability. Only one male and one female were collected and examined under compound microscope. No asymmetries were observed and the only differences between the male and the female are all part of a normal sexual dimorphism in this family.

Etymology. The new species is named in honour of Dr Adrian Pinder, from the Department of Environment and Conservation (DEC) of the Western Australian 


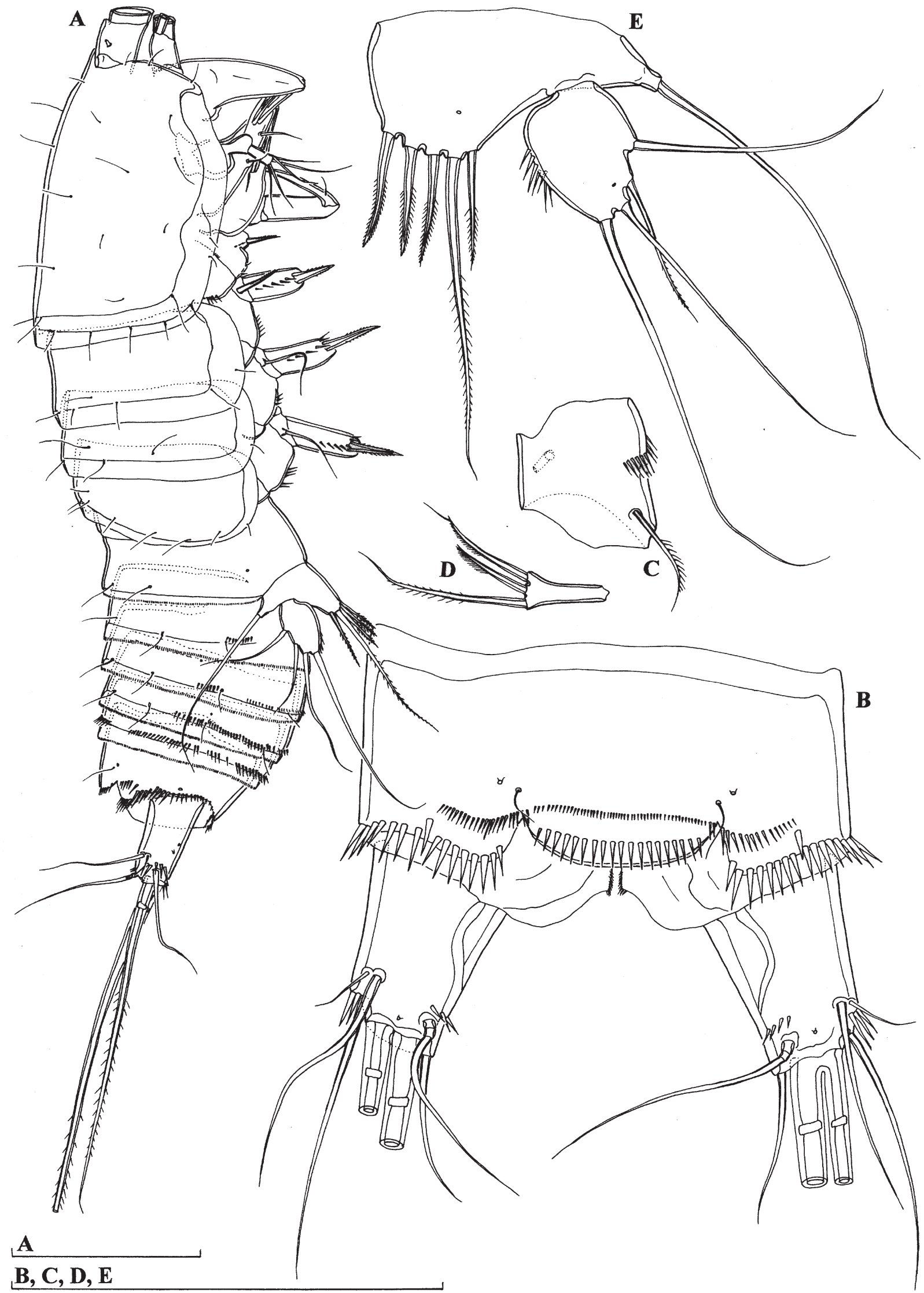

Fig. 5. Nitocrellopsis pinderi sp. nov., holotype female: A - habitus, lateral view; B - anal somite and caudal rami, dorsal view; C - first antennular segment; D - exopod of antenna; E - fifth leg. Scales $=0.1 \mathrm{~mm}$. 


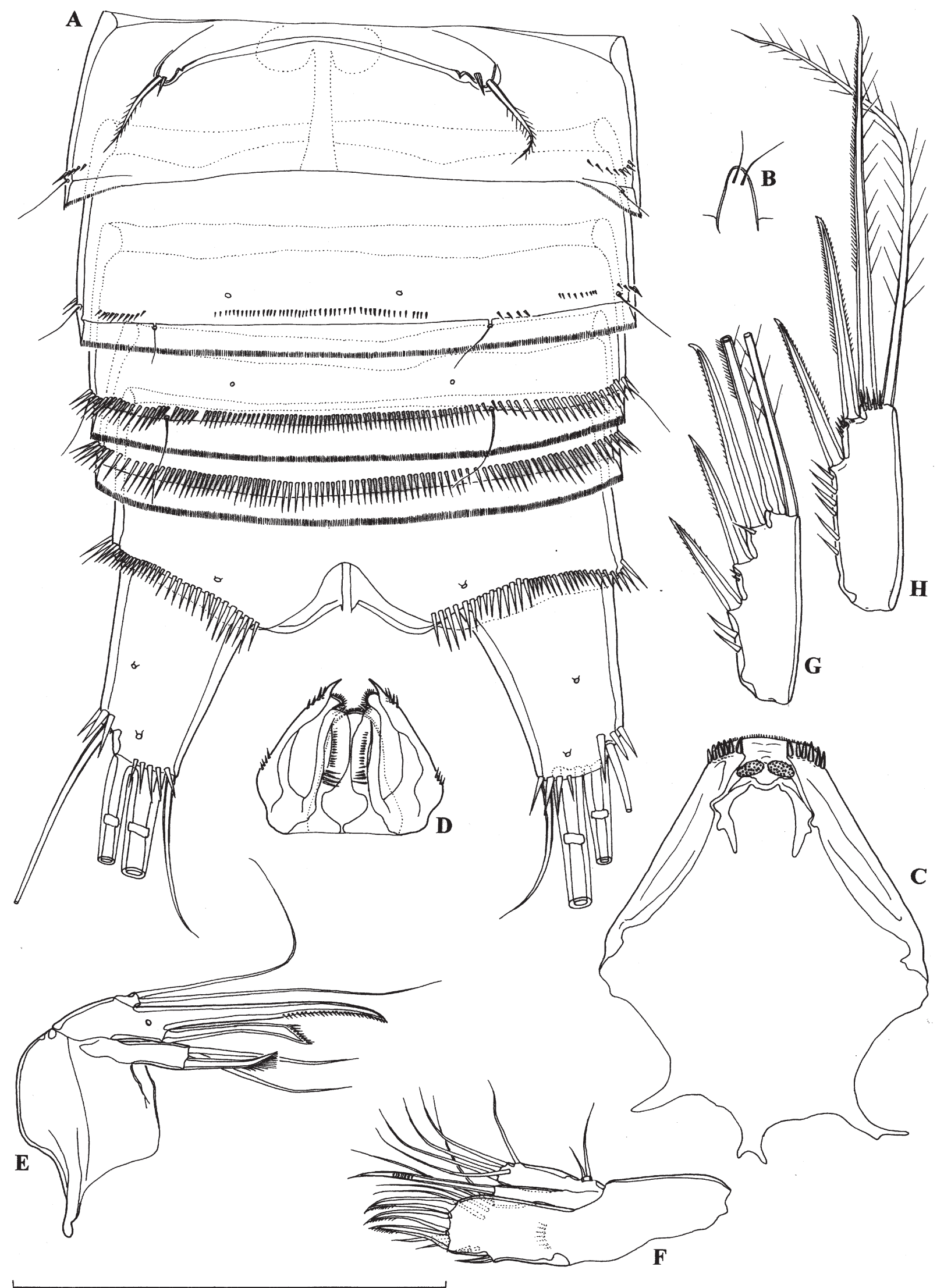

Fig. 6. Nitocrellopsis pinderi sp. nov., holoype female: A - abdomen, slightly compressed, ventral view; B - rostrum, dorsal view; $\mathrm{C}$ - labrum; D - paragnaths; E-maxilla; F-maxillula; $\mathrm{G}$ - third exopodal segment of second swimming leg; $\mathrm{H}$ - third exopodal segment of third swimming leg. Scale $=0.1 \mathrm{~mm}$. 


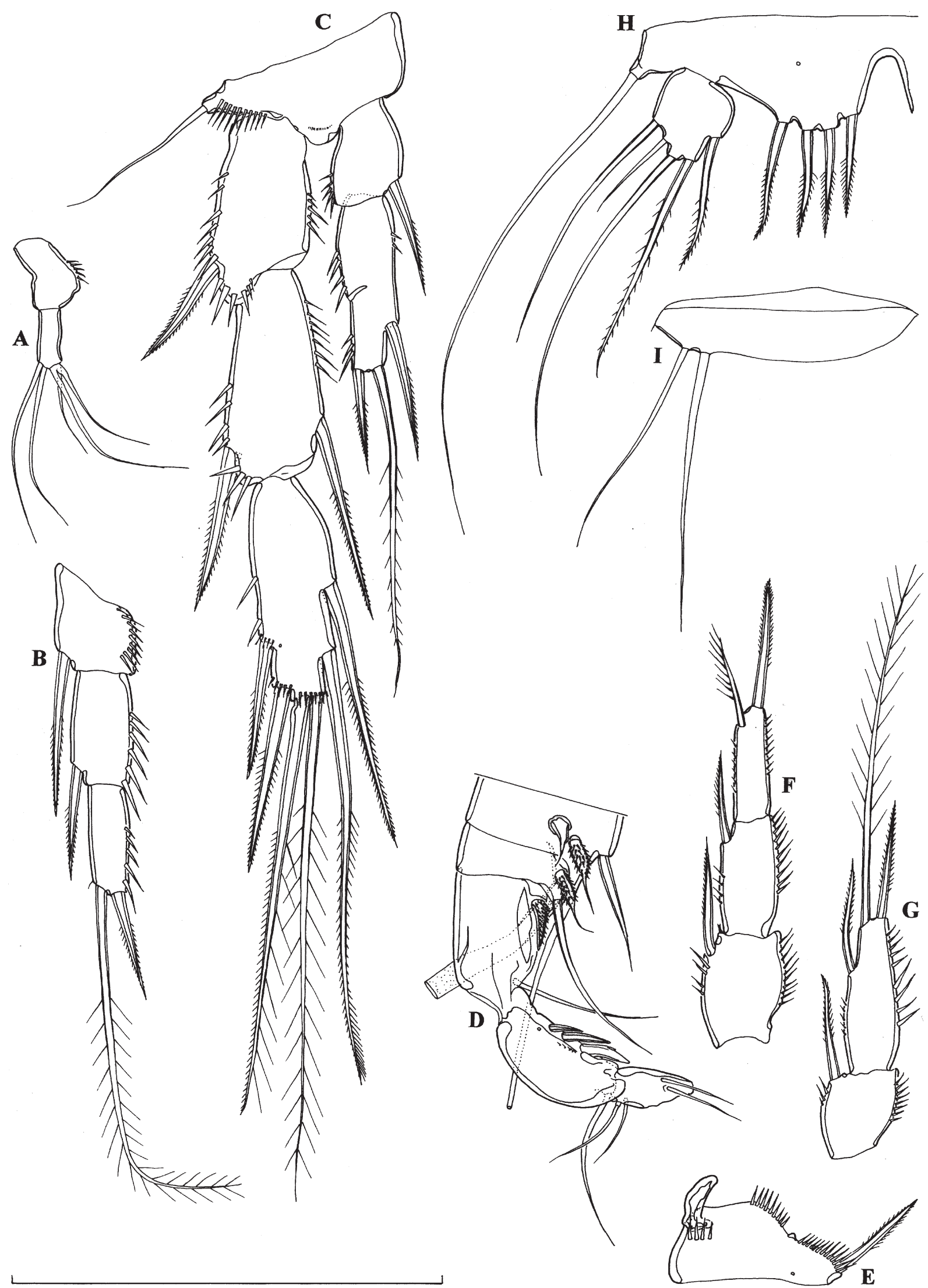

Fig. 7. Nitocrellopsis pinderi sp. nov., A-C, holotype female; D-I, male from bore MNRB 15: A - mandibular palp; B - endopod of third swimming leg; C - fourth swimming leg; D - part of antennula; E - basis of first swimming leg; F - endopod of third swimming leg; $\mathrm{G}$ - endopod of fourth swimming leg; $\mathrm{H}$ - fifth leg; I - sixth leg. Scale $=0.1 \mathrm{~mm}$. 
Goverment, who kindly supported this study financially. The name is a noun in the genitive singular.

Remarks. As mentioned in the remarks section for the above described Nitocrellopsis halesi sp. nov., this is the sister species of $N$. pinderi sp. nov. Numerous morphological similarities include somite ornamentation, armature patterns of the swimming legs and the fifth leg, as well as the shape and armature of the antennula, antenna and almost all mouth appendages. The main differences between $N$. halsei and $N$. pinderi can be observed in the body size and habitus appearance, caudal rami shape and size, presence/absence of large lateral pores on fourth pedigerous somite, number of spinules on the anal operculum, number of setae on the madibular endopod, and shape of the exopod of the fifth leg.

The type locality of $H$. pinderi is actually closer to the type locality of $N$. halsei than to its second known locality, and although the two species have not yet be found to live sympatricly that possibility is very plausible. All three localities are in a very small area and probably in the same calcrete body, although we know very little about the actual complexity of these habitats and some recent studies suggest that they are much patchier than previously suspected (Cooper et al., 2008; Guzik et al., 2008). A significant difference in size between these two closely related species is very characteristic of selective pressures associated with recent sympatric distribution, and it is well documented in this region for many sympatric sister species of diving beetles (Leys et al., 2003; Leys and Watts, 2008).

\section{Nitocrellopsis operculata sp. nov. (Figs. 8-10 and 12)}

Type material. Holotype, adult female dissected on one slide (WAM C37322); allotype, adult male dissected on one slide (WAM C37323); paratypes, one adult male and one adult female dissected together on one slide (WAM C37324), seven adult males + nine adult females + four copepodids in one vial in 70\% alcohol (WAM C37325), and three adult males + four adult females on one SEM stub (WAM C37325A); Australia, Western Australia, Pilbara region, Colgara Borefield, bore NWSLK176, 27 August 2003, leg. Jim Cocking and Mike Scanlon (DEC), $22^{\circ} 58^{\prime} 00^{\prime \prime S} 116^{\circ} 51^{\prime} 00^{\prime \prime E}$.

Description. Female (holotype). Total body length, measured from tip of rostrum to posterior margin of caudal rami (excluding caudal setae), $0.611 \mathrm{~mm}$. Preserved specimen colourless. Nauplius eye absent. Prosome comprising cephalothorax with completely fused first pedigerous somite, and three free pedigerous somites; urosome five-segmented, comprising fifth pedigerous somite, genital double somite and three abdominal somites. Sclerotized joint (almost as pseudosomite) present between prosome and urosome. Habitus (Fig. 8A) spindle-shaped, robust, without distinct demarcation between prosome and urosome; prosome/urosome ratio 1.2 and greatest width from dorsal view at posterior end of cephalothorax. Body length/width ratio about 3.7; cephalothorax 1.6 times as wide as genital somite. Free pedigerous somites without pronounced lateral or dorsal expansions. Integument weakly chitinized, but cuticular windows clearly visible dorsally on first and second free prosomal somites, as well as laterally on genital double somite (at anterior half) and first free abdominal somite. Rostrum minute, membranous, linguiform, not reaching first fifth of first antennular segment, about 1.5 times as long as wide and not demarcated at base; ornamented with two dorsal sensilla.

Cephalothorax (Fig. 8A) almost triangular in dorsal view, about as long as wide; represents $26 \%$ of total body length. Surface of cephalic shield ornameted with numerous large sensilla, while tergites of three free pedigerous somites with only a few large sensilla. First and second free prosomite additionally ornamented with short row of minute spinules dorsally, just behind cuticular windows. Third free pedigerous somite without spinules or windows, ornamented only with four dorsal and six lateral (three on each side) sensilla. Hyaline fringes of all prosomites smooth and all prosomites additionally ornamented with numberous arched rows of extremely minute spinules (not drawn). Fifth pedigerous (first urosomal) somite (Fig. 8A) ornamented with two dorsal and two lateral sensilla (one on each side), as well as with two dorsal pores; hyaline fringe finely serrated dorsolaterally.

Genital double somite (Figs. 8A and 9A) as long as wide (ventral view), with suture visible dorsolaterally and furnished with two parallel rows of small spinules and three sensilla laterally, as well two sensilla dorsally; additionally ornamented with posterior row of somewhat larger spinules (which interrupted ventrally) along with eight large sensilla (two dorsal, two ventral and two on each side laterally) and three lateral parallel rows of minute spinules in between; hyaline fringe finely serrated both ventrally and dorsally; proximal part of double somite with one large cuticular window on each side laterally. Female genital complex with single large copulatory pore, weakly sclerotized and almost stright copulatory duct and two small ovoid seminal receptacles. Single small genital aperture covered by fused reduced sixth legs (Fig. 9A), represents 33\% of somite width. Third urosomite (first free abdominal somite) ornamented with posterior uninterrupted row of spinules (although ventral spinules much smaller than lateral), along with ten large posterior sensilla (two dorsal, two ventral and three lateral on each side), two large ventrolateral cuticular windows, and several short rows of minute spinules laterally; hyaline fringe finely serrated. Fourth urosomite (preanal somite) ornamented only with uninterrupted posterior row of larger spinules and with three lateral short rows of minute spinules; hyaline fringe also finely serrated. Anal somite (Figs. 8A and 9A) ornamented with pair of large dorsal sensilla, two ventral and two lateral (one on each side) small cuticular pores, transverse row of large spinules along posterior margin (dorsal ones not longer than ventral), five short rows of minute spinules ventrally at proximal part, and two short rows of minute spinules laterally. Anal operculum convex, not reaching poster ior end of anal somite, represents $48 \%$ of somite's 
width, ornamented with 18 small spinules near posterior margin. Anal sinus without visible ornamentation. All ursomites additionally ornamented with numerous arched rows of extremely minute spinules, most of which not drawn.

Caudal rami (Fig. 9A) small, much shorter than anal somite, about 1.5 times as long as wide (ventral view), slightly divergent, with space between them more than one ramus width; armed with seven armature elements (three lateral, one dorsal and three apical). Ornamentation consists of three spinules at base of distal lateral seta, posterior row of three spinules ventrally and one lateral and two ventral pores. Dorsal seta relatively long, inserted near posterior margin, about twice as long as caudal ramus, triarticulate at base. Proximal lateral seta about half as long as dorsal seta, arising dorsolaterally at $2 / 3$ of ramus length. Distal lateral seta 1.2 times as long as ramus and 1.4 times as long as proximal lateral seta, arising laterally at $3 / 4$ of ramus length. Dorsal seta and all three lateral setae smooth. Inner apical seta also smooth, approximately as long as ramus. Middle apical seta strongest, with breaking plane, pinnate at distal end, about twice as long as outer apical seta and 0.5 times as long as total body length. Outer apical seta also with breaking plane and pinnate at distal end.

Antennula (Fig. 8B) eight-segmented, joined to cephalotholax with small triangular pseudosegment laterally, approximately 1.4 times as long as cephalothorax. Strong aesthetasc on fourth segment, not fused basally to adjacent large seta and reaches beyond tip of appendage for length of last segment; slender aesthetasc apically on eighth segment fused basally with two apical setae, forming apical acrothek. Setal formula: 1.9.7.3.2.3.4.7. Only seta on first segment unipinnate, all other setae smooth. Two lateral setae on seventh segment and four lateral setae on eighth segment biarticulate basally. All setae uniarticulate and without breaking planes. First segment ornamented with cuticular tube pore on anterior surface and diagonal row of spinules along inner margin proximally; other segments without any ornamentation. Length ratio of antennular segments, from proximal end, $1: 2: 1.4: 1.6: 0.9: 1: 0.7: 1.3$.

Antenna (Fig. 9B) short, about half as long as cephalothorax, composed of coxa, basis, two-segmented endopod and one-segmented exopod. Coxa extremely short, unornamented. Basis 1.6 times as long as wide and nearly four times as long as coxa, ornamented with row of spinules along inner margin distally, unarmed. First endopodal segment about 2.2 times as long as wide and 1.3 times as long as basis, unornamented and unarmed. Second endopodal segment 1.4 times as long as first endopodal segment, with two surface frills subdistally, armed laterally with two spines flanking thin seta; apical armature consisting of five geniculate setae, longest one fused basally to additional smaller seta, bearing proximal tuft of fine setules and bipinnate distally; ornamentation consists of long spinules along anterior surface. Exopod very slender, cylindrical, half as long as basis, unornamented, armed with two apical setae; inner seta bipinnate, 2.5 times as long as segment and twice as long as outer unipinnate seta.

Labrum (Fig. 8C) large compared to cephalothorax, trapezoidal, rigidly sclerotized, with relatively short and somewhat concave cutting edge, ornamented subapically with two rows of seven strong spinules (innermost ones strongest) and apically with minute spinules. Two small ovoid fields of gustatory papillae on dorsal (posterior) surface, between rows of strong spinules and strongly chitinized medial horseshoe.

Paragnaths ellipsoid, about twice as long as wide, with group of spinules of different length apically, few spinules laterally, as well as group of four large spinules on proximal inner part of each lobe, continuing with row of much smaller spinules.

Mandibula (Fig. 9C) with narrow cutting edge of elongated coxa, armed with three coarse teeth ventrally, one unipinnate seta dorsally and many small teeth in between (one tooth at middle stronger and longer than others). Palp uniramous, comprising basis and onesegmented endopod. Basis with inflated central part, about 1.6 times as long as wide, unarmed, ornamented with three spinules on inner margin. Endopod slender and unornamented, about 0.87 times as long as basis and twice as long as wide; armed with five slender and smooth setae apically.

Maxillula (Fig. 8D) with large praecoxa, arthrite rectangular, unornamented, armed with two anterior surface setae, three lateral and four apical elements (probably three spines and one seta). Coxal endite much shorter than praecoxal arthrite, armed with one curved and stout, unipinnate seta and two smooth, slender setae. Basis considerably shorter than coxal endite, armed with five smooth setae apically and subapically. Endopod represented by minute segment, armed with single smooth seta apically.

Maxilla (Fig. 9D) with proximal endite of syncoxa completely reduced; distal endite well developed, highly mobile, armed with one curved pinnate spine and two smooth subequal setae apically, which 1.7 times as long as spine; ornamentation of suncoxa consists of arched row of large spinules near distal outer corner. Basis drawn out into long claw, with shorter spiniform and curved seta at base, ornamented with cuticular pore basally and minute spinules along convex margin. Endopod represented by minute segment, armed with two long and smooth, subequal apical setae.

Maxilliped (Fig. 8E) with long syncoxa, ornamented with longitudinal row of minute spinules along inner margin and armed with one bipinnate seta subapically. Basis about 2.3 times as long as wide and 1.3 times as long as syncoxa, unornamented and unarmed. Endopod represented by long curved claw, longer than basis, ornamented with row of spinules along concave side distally, accompanied at base by thin smooth and short seta.

Swimming legs with three-segmented exopod and first three also with three segmented endopod (Figs. 8F, 9E, 9F and 10A). Endopod of fourth swimming leg two segmented (Fig. 10B). Armature formula of swimming legs 
as follows (for preultimate segments - inner/outer elements; for ultimate segments - inner/terminal/outer elements):

\begin{tabular}{lccccccc}
\hline & \multicolumn{3}{c}{ Exopod } & & \multicolumn{3}{c}{ Endopod } \\
\cline { 2 - 4 } \cline { 6 - 8 } Segments & 1 & 2 & 3 & & 1 & 2 & 3 \\
\hline First leg & $0 / 1$ & $1 / 1$ & $0 / 2 / 3$ & & $1 / 0$ & $0 / 0$ & $1 / 1 / 1$ \\
Second leg & $0 / 1$ & $1 / 1$ & $1 / 2 / 3$ & & $1 / 0$ & $1 / 0$ & $1 / 1 / 1$ \\
Third leg & $0 / 1$ & $1 / 1$ & $1 / 2 / 2$ & & $1 / 0$ & $1 / 0$ & $1 / 1 / 1$ \\
Fourth leg & $0 / 1$ & $1 / 1$ & $2 / 2 / 2$ & & $1 / 0$ & $1 / 1 / 1$ & - \\
\hline
\end{tabular}

Intercoxal sclerites of all swimming legs with concave and smooth distal margin. Praecoxa with row of long spinules along outer posterior margin. Coxa of first swimming leg (Fig. 8F) ornamented with three rows of spinules of different size (one along outer margin, one along distal margin and one inner distal corner); coxae of other legs unornamented and all coxae unarmed. Basis ornamented with very long spinules on outer margin on distal margin between exopod and endopod, armed with outer spine on first and second swimming legs and with outer smooth seta on third and fourth legs; basis of first leg with short and stout spine near inner distal corner and several spinules at its base, as well as additional row of spinules on inner margin. Exopods and endopods of all swimming legs ornamented with long spinules along outer margin and some segments also with spinules along inner and distal margin. First exopodal segment of all legs only slightly shorter than second exopodal segment. First endopodal segment of first swimming leg (Fig. 8F) stout, about three times as long as wide, somewhat longer than first two exopodal segments. Endopods of second and third swimming legs (Figs. 9E and 10A) reaching $1 / 3$ of third exopodal segment in length; while endopod of fourth swimming leg (Fig. 10B) reaching middle of second exopodal segment. All setae on exopods and endopods strong and spiniform, except minute inner seta on third endopodal segment of first leg and apical endopodal seta in other legs, as well as inner apical seta on exopods of second, third and fourth legs.

Fifth leg (Figs. 8G and 8H) biramous, baseoendopods not fused. Baseoendopod with outer basal seta long and smooth, arising from long setophore. Endopodal lobe very wide, convex, extending to half of exopod in length, ornamented only with small pore at middle, armed with three stout, bipinnate setae, with length ratio (from inner side) $1: 0.9: 0.8$. One leg with innermost and middle setae on baseoendopod fused basally. Exopod small and round, slightly wider than long, ornamented with slender spinules along inner margin and small pore at half of its length, closer to outer margin, armed with four setae; first and third seta from inner side pinnate and strong, other two setae smooth and slender. Length ratio of four exopodal setae, from inner side, $1: 0.5: 0.3: 0.4$.

Sixth legs (Fig. 9A) completely fused, indistinct, forming simple operculum covering single gonopore, without any ornamentation, each armed with outer short and smooth seta and minute inner spine.

Male (allotype). Body length, excluding caudal setae, $0.555 \mathrm{~mm}$. Habitus (Fig. 10C), ornamentation of prosomites, rostrum, colour and nauplius eye similar to female. Prosome/urosome ratio 1.1, greatest width at posterior end of cephalothorax, body length/width ratio about 3.8; cephalothorax 1.7 times as wide as genital somite. Urosomites ornamentation similar to female, although posterior row of spinules not of smaller size ventrally on third urosomite. Anal operculum with 17 small posterior spinules.

Caudal rami (Fig. 10C) with the same armature and ornamentation as in female, although slightly shorter.

Antennula (Fig. 10D) long and slender, ten-segmented, strongly geniculate, with geniculation between seventh and eighth segment; ornamented with cuticular tube pore and row of spinules on first segment. Sevent and eight segments with inner margins strongly chitinized, with several smaller and larger spine-like structures. Very long aesthetasc on apical acrothek of fifth segment (homologue to aesthetasc on fourth segment in female); very slender aesthetasc on tenth segment apically also fused to two apical setae. First two and last two segments similar to female, although last segment somewhat shorter. Setal formula: 1.10.7.2.7.2.2.1.4.7. Majority of setae smooth and slender; seta on first segment pinnate; two setae on fifth, one on sixth and one on seventh segment very short and spiniform and all covered with several rows of strong spinules, except proximal one on fifth segment, which smooth. Only three lateral setae on tenth segment and two setae on ninth segment barticulating on basal part.

Antenna, labrum, paragnaths, mandibula, maxillula, maxilla, maxilliped, second swimming leg (Fig. 10F), third swimming leg (Fig. 10F) and fourth swimming leg same as in female.

First swimming leg (Fig. 10E) with short, spatulashaped and smooth modified inner spine on basis, 0.7 times as long as basis and directed outwards.

Fifth legs (Fig. 10H) with baseoenopods not fused. Baseoendopod very short and broad, unornamented and armed with single strong seta. Exopod without ornamentation along inner margin, but with additional spiniform inner seta, about 2.2 times as long as exopod; other four setae smooth and short.

Sixth leg (Fig. 10H) not fused basally to each other and to somite, armed with two smooth short setae; inner seta nearly twice as long as outer.

Variability. Body length of females ranges from $0.538 \mathrm{~mm}$ to $0.6485 \mathrm{~mm}(0.591 \mathrm{~mm}$ average; $n=16)$, while in males it ranges from $0.462 \mathrm{~mm}$ to $0.570 \mathrm{~mm}(0.522 \mathrm{~mm}$ average; $n=12$ ). One paratype female has four setae on the baseoendopod of the fifth leg (Fig. 9G) on both sides. One paratype male lacks any armature on the baseoendopod of one fifth leg, while the other one is normally armed. The holotype female has the innermost and middle setae on the left fifth leg baseoendopod fused basally (Fig. 8H), while the right fifth leg is normal (Fig. 8G). Although all cuticular windows look similar under a compound microscope, when examined with a scanning electron microscope it becomes clear that only those on prosomites can be seen on the surface, while the urosomal ones are internal (Fig. 12A). Number and density 


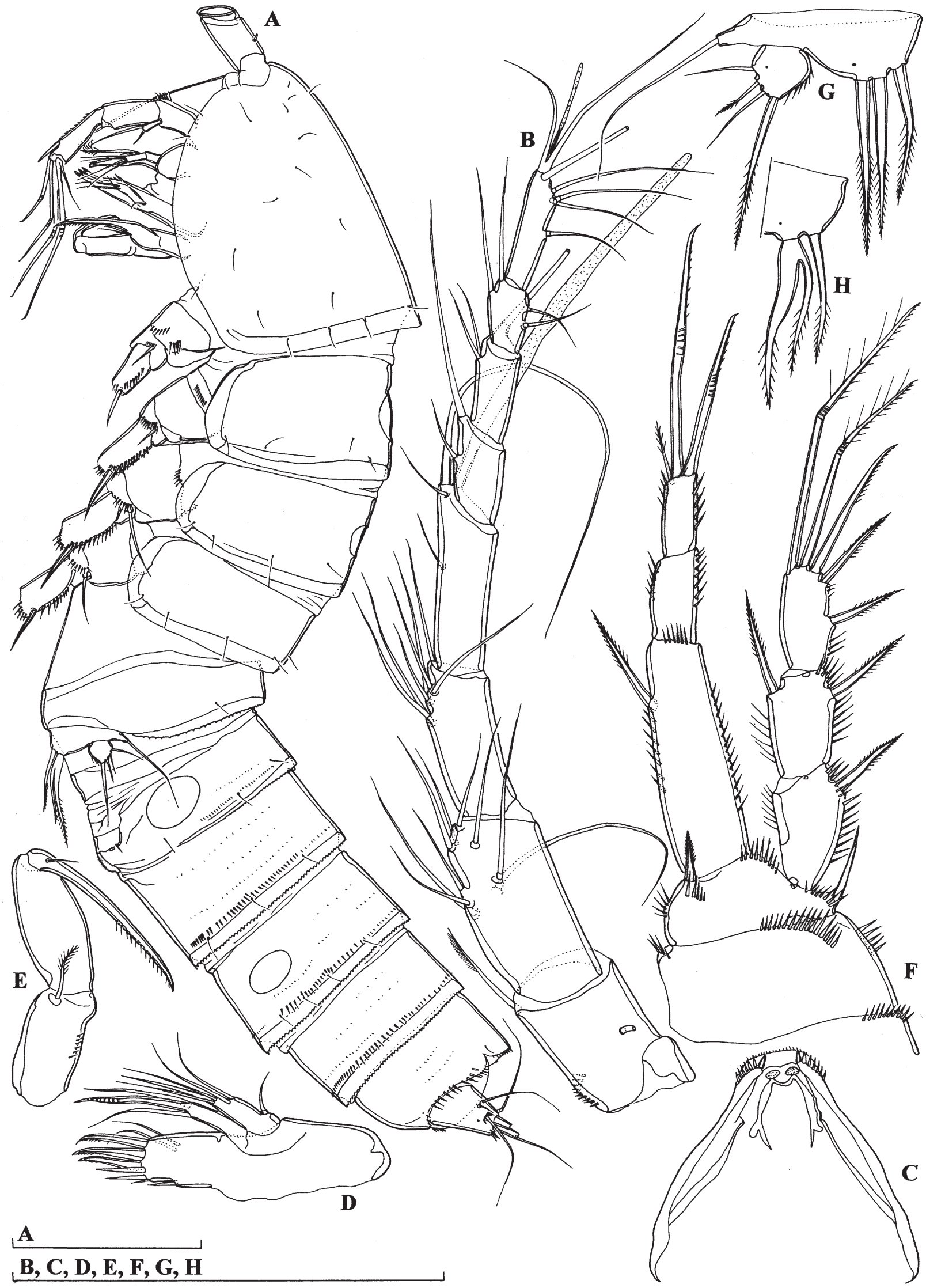

Fig. 8. Nitocrellopsis operculata sp. nov., holotype female: A - habitus, lateral view; B - antennula; C-labrum; D-maxillula; $\mathrm{E}$ - maxilliped; F - first swimming leg; $\mathrm{G}$ - right fifth leg; $\mathrm{H}$ - baseoendopod of left fifth leg. Scales $=0.1 \mathrm{~mm}$. 


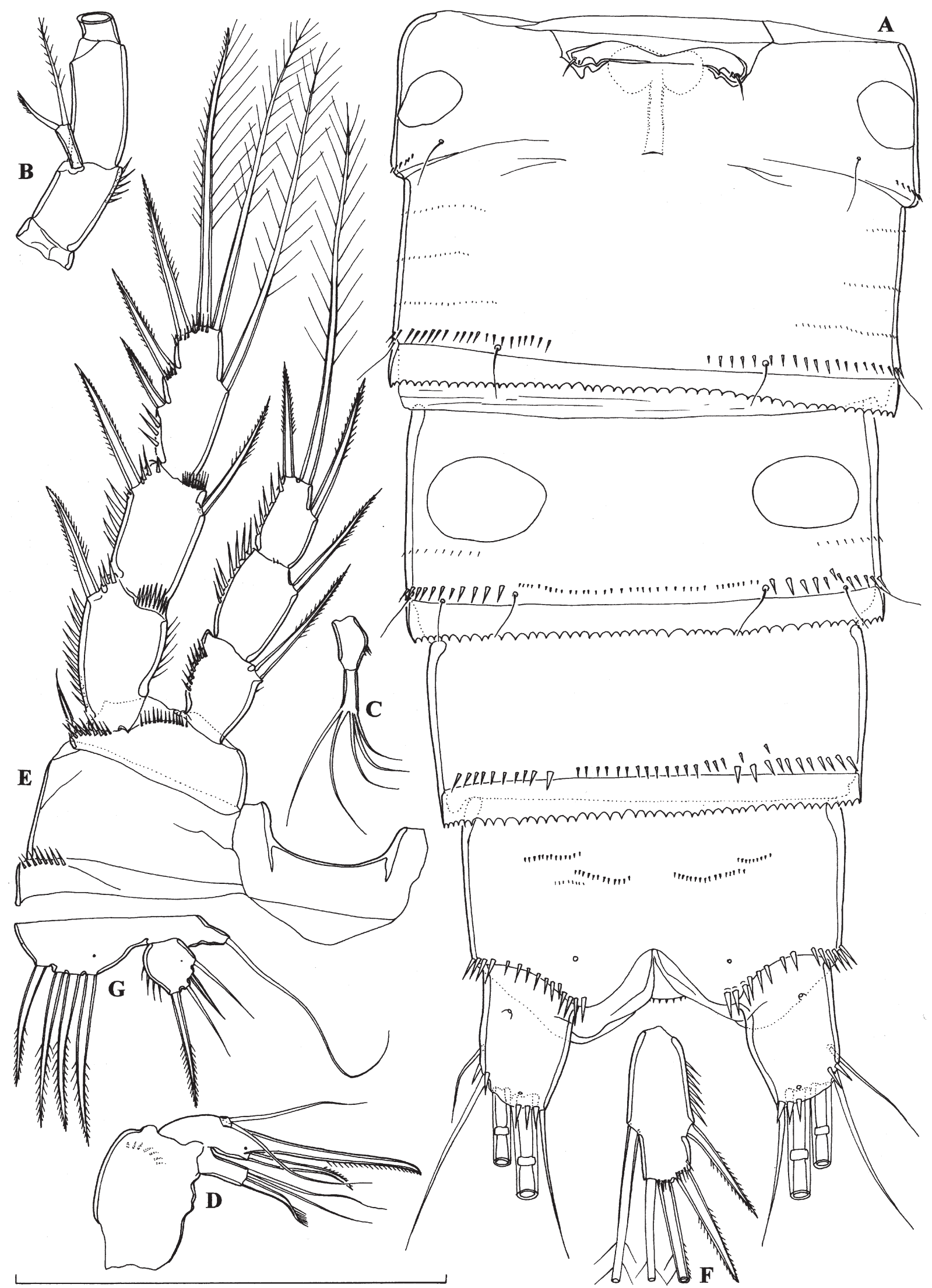

Fig. 9. Nitocrellopsis operculata sp. nov., A-F, holotype female; G, paratype female (0.606 mm long, WAM C 37324): A - abdomen, ventral view; $\mathrm{B}$ - antenna; $\mathrm{C}$ - mandibular palp; D - maxilla; $\mathrm{E}$ - second swimming leg; $\mathrm{F}$ - third exopodal segment of third swimming leg; $\mathrm{G}$ - fifth leg. Scale $=0.1 \mathrm{~mm}$. 


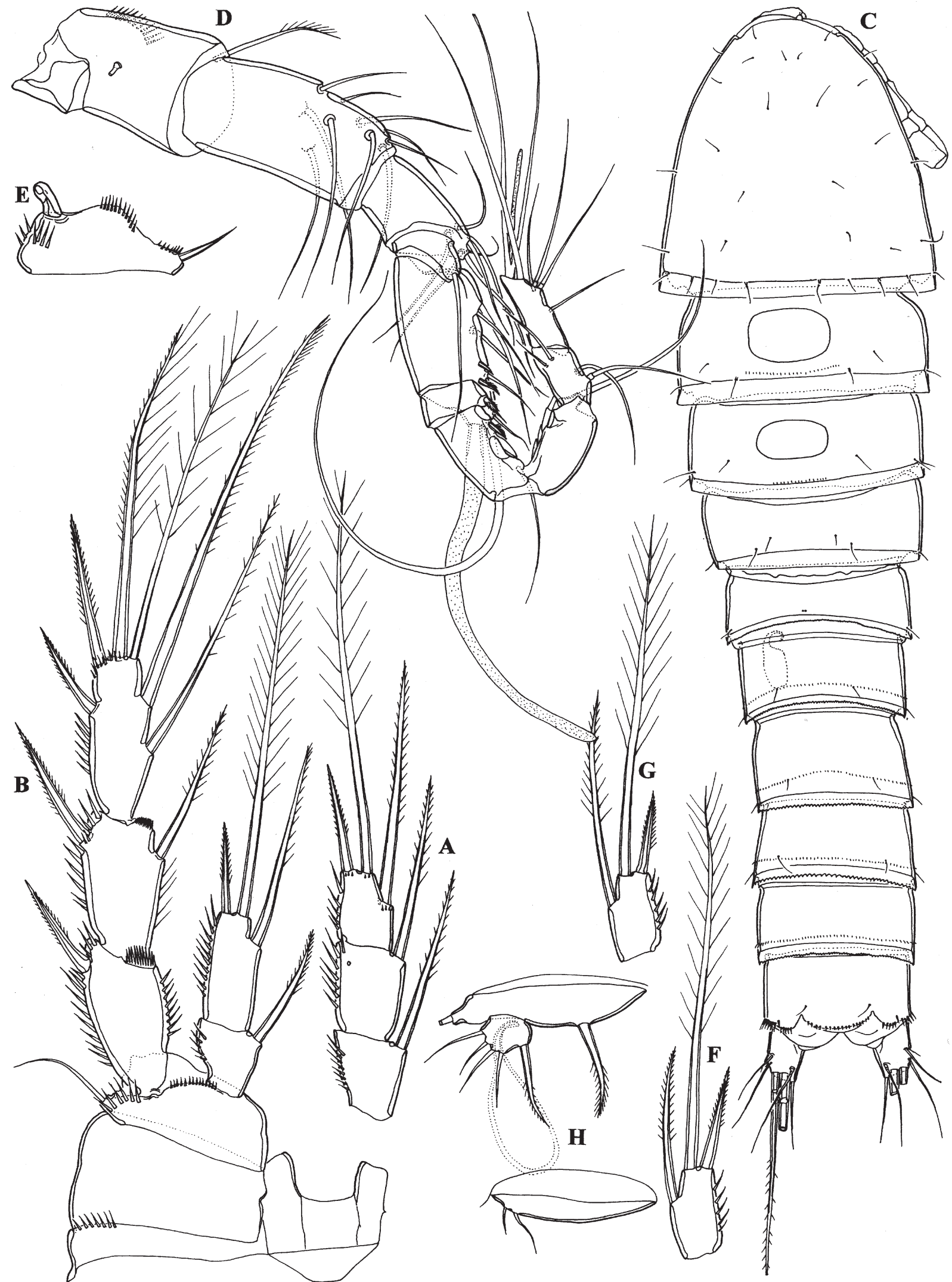

C

A, B, D, E, F, G, H

Fig. 10. Nitocrellopsis operculata sp. nov., A-B, holotype female; C-H, allotype male: A - endopod of third swimming leg; B - fourth swimming leg; $\mathrm{C}$-habitus, dorsal view; $\mathrm{D}$-antennula; $\mathrm{E}$ - basis of first swimming leg; $\mathrm{F}$-endopod of third swimming leg; $\mathrm{G}$ - endopod of second swimming leg; $\mathrm{H}$ - fifth and sixth leg, with spermatophore visible inside the body. Scales $=0.1 \mathrm{~mm}$. 

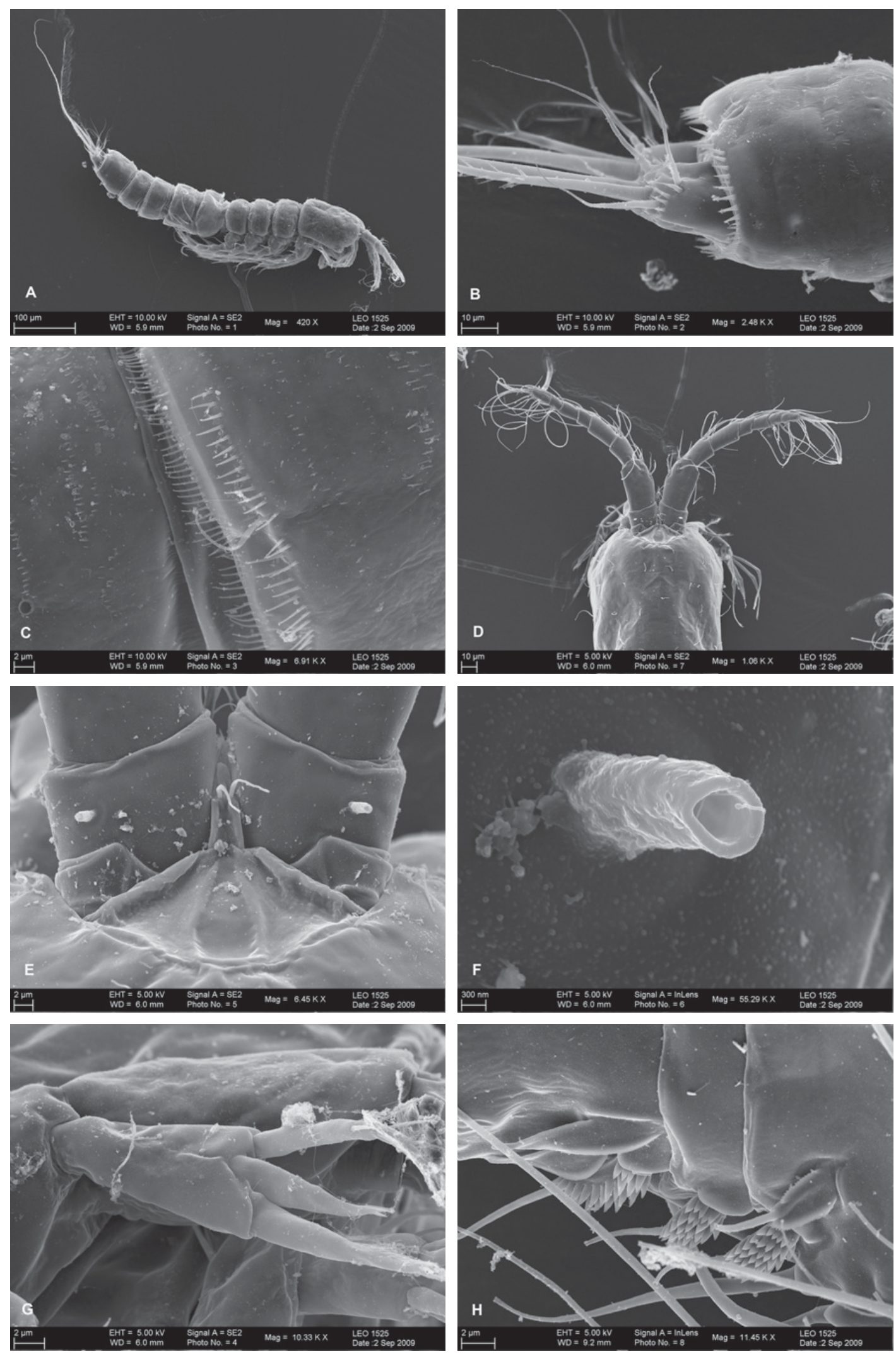

Fig. 11. Nitocrellopsis halsei sp. nov., SEM photographs, A-C and G, paratype female ( $0.581 \mathrm{~mm}$ long); D-F, another paratype female $(0.554 \mathrm{~mm}) ; \mathrm{H}$, paratype male $(0.546 \mathrm{~mm})$ : A - habitus, lateral view; B - anal somite and right caudal ramus, lateral view; $\mathrm{C}-$ hyaline fringe of genital somite, lateral view; D - cephalothorax and antennulae, dorsal view; E - rostrum and first antennular segments, dorsal view; $\mathrm{F}$ - tubular pore on first antennular segment; $\mathrm{G}$ - exopod of antenna; $\mathrm{H}$ - transformed spines on fifth to seventh antennular segments. 

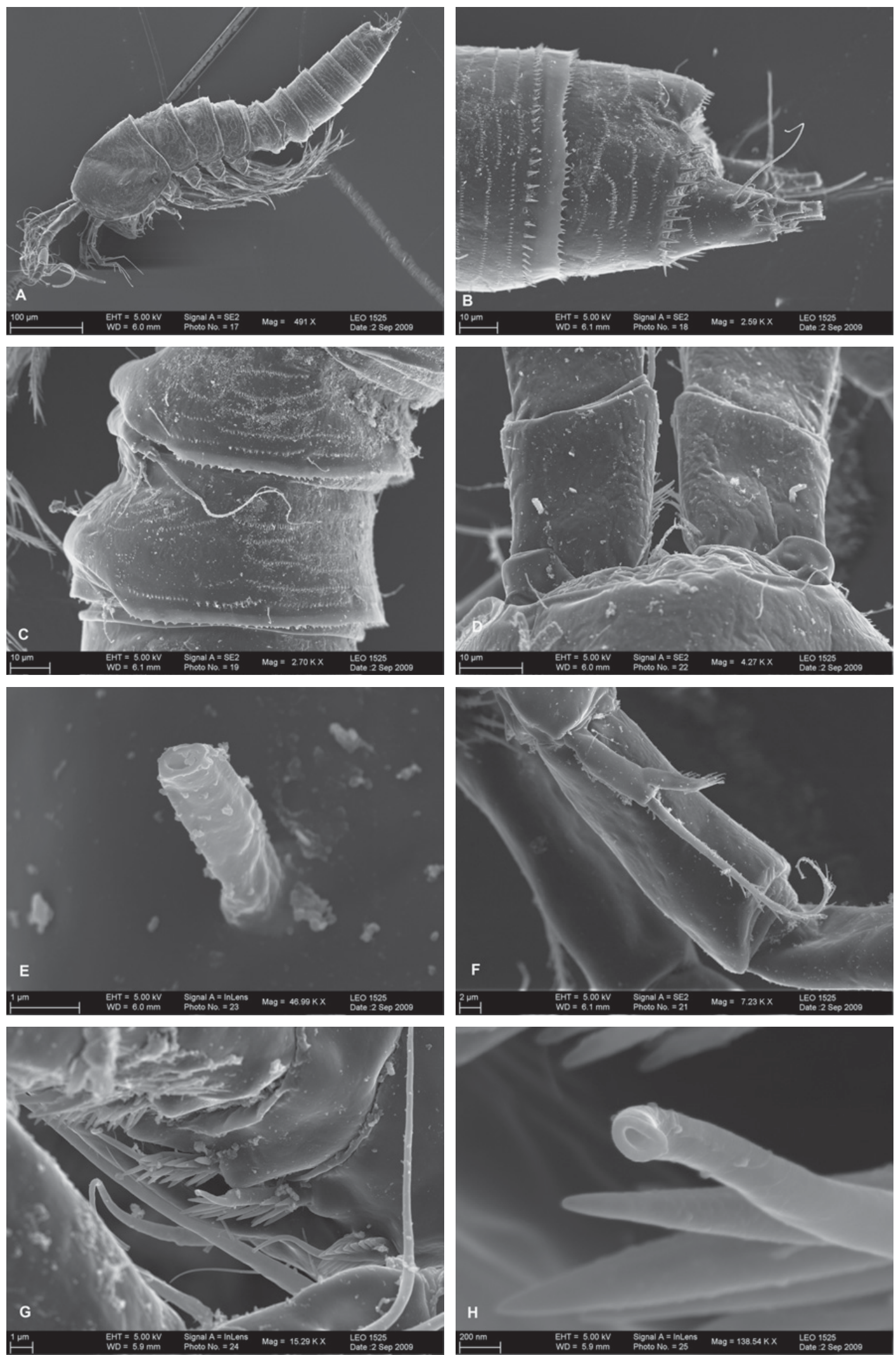

Fig. 12. Nitocrellopsis operculata sp. nov., SEM photographs, A-C and F, paratype female $(0.579 \mathrm{~mm}$ long); D and E, another paratype female $(0.606 \mathrm{~mm})$; F and $\mathrm{G}$, paratype male $(0.527 \mathrm{~mm})$ : A - habitus, lateral view; $\mathrm{B}$ - anal somite and left caudal ramus, lateral view; $\mathrm{C}$ - fifth pedigerous and genital somites, lateral view; D - rostrum and first antennular segments, dorsal view; E - tubular pore on first antennular segment; $\mathrm{F}$ - exopod of antenna; $\mathrm{G}$ - transformed spines on fifth to seventh antennular segments; $\mathrm{H}$ - pore on tip of transformed spine on fifth antennular segment. 
of minute spinules on urosomites is variable (Figs. 12B and $12 \mathrm{C}$ ), but not as much as in the previous two species. All examined specimens also have tubular pores on the first antennular segment (Fig. 12D), which has somewhat narrower opening than in the previous two species (Fig. 12E). One paratype female has somewhat longer apical exopodal seta on the antenna (Fig. 12F). Examination of the transformed spiniform elements on the male antennua of one paratype with a scanning electron microscope shows that they are very similar to those in the previous two species, although their spinules are longer and not so scaly (Fig. 12); all four transformed elements also have a slender distal part, with pore on tip (Fig. 12H).

Etymology. The new species name comes from characteristic lateral cuticular windows on the genital somite. It is an adjective, agreeing in gender with the feminine generic name.

Remarks. Nitocrellopsis operculata sp. nov. can be distinguished from all other congeners by the reduced armature of the antennal exopod (Figs. 9B and 12F), which is an autapomorphic feature in this group, but has probably arisen independently a number of times in freshwater ameirids. This will be discussed further in the Discussion section below. Also no other species of Nitocrellopsis has cuticular windows on prosomal or urosomal somites, or six elements on the third exopodal segment of the second leg. This species shares with the other two new Australian representatives several characters, including three outer spines on the first exopodal segment of the first and second legs and two inner elements on the third exopodal segment of the fourth leg, but these are plesiomorphic features and as such not pointing towards a closer phylogenetic relationship, even though they don't share the second one with any other congener and the third one with only one other species ( $N$. elegans (Chappuis and Rouch, 1959)). It is quite clear that they are only remotely related.

\section{Discussion}

The phylogenetic analysis of the Nitocrellopsis Galassi, De Laurentiis \& Dole-Olivier, 1999 species performed here is a cladistic one, using Rachet Island in the NONA computer program (Goloboff, 1999) to search for the most parsimonious tree. Character selection for this study was influenced mostly by the data available in published descriptions, as well as the choice of outgroup taxa. I was able to score 43 informative characters and two uninformative ones were also added in the cladistic analysis (Table 1), although most uninformative characters were left out. The list of characters and their states is given in the Material and methods section above. The majority of them (28 characters) are related to the swimming legs armature, partly as a consequence of a generally unsatisfactory practice of describing new species in this group virtually exclusively on leg characters and with almost no consideration of cephalic appendages, habitus shape or somite ornamentation (Lee and Huys, 2002). Here
I should discuss a couple of issues related to the problems of recognizing homologous structures in different taxa, characters weighting, and usability and robustness of different morphological structures for the reconstruction of phylogenetic relationships in freshwater ameirids. As I pointed out in the Introduction section above, this work is a continuation of Karanovic and Hancock (2009), which was the first attempt ever at a phylogenetic analysis of ameirid copepods, pending the revision of the family. Although, monophily of many genera and species groups of ameirids cannot be fully assessed before a comprehensive revision of the family, based on phylogenetically informative morphological and molecular characters, smaller studies of different groups and genera will contribute to the character evaluation and hopefully make the revision easier.

Recognizing homologous structures in different species was the hardest part and in some cases (the male fifth leg endopod, for example) almost impossible. I used indirect evidence from three chosen outgroups to determine homologues armature elements in more reduced species of Nitocrellopsis. For example, whether the apical seta on the third endopodal segment of the third leg in N. halsei sp. nov. (Fig. 3A) represents an ancestral outer or inner apical seta (both are present in our first outgroup species, Biameiropsis barrowensis Karanovic, 2006) it is impossible to say with any certainty. However, the condition of these two armature elements in our second outgroup, Nitokra lacustris pacifica Yeatman, 1983, shows that it is the outer seta that becomes more reduced first, so we assume the evolutionary trend would continue in the same place with more drastic reductions in subterranean environments, where one of the two is completely lost. Thus, I believe, the only apical seta in $N$. halsei is the ancestral inner apical seta (see Character 29; Table 1), although the possibility that in some representatives studied here the ancestral inner apical seta is reduced and the ancestral outer apical seta present cannot be discarded completely. Homologues armature elements were named according to their position in the outgroup with most plesiomorphic characters, in this case $B$. barrowensis, and one should consult Karanovic (2006) for more details about the morphology of this species and in order to more easily follow the cladistic analysis discussed here. For example, Characters 27 and 28 (Table 1) are called "middle inner seta" and "distal inner seta" respectively, because there is one more seta (proximal) in B. barrowensis, even though that one was not coded in our matrix as it would be uninformative. Also, when the number of setae on the maxillular endopod is reduced from two to one (Character 7) it is very hard to know which one of these tiny setae is lost and which one present, as the endopod is also reduced in size. A similar challenge in the future revision of the family will be to determine which segment is lost in the two segmented endopod of the fourth leg, the ancestral first or second, without any development studies. For the current analysis that was not so important, assuming that it was the same segment in all species (Character 30), but this is one area where molecular characters may help in the future 
as a substitute for the time-consuming studies of the development.

Two of the three new species described in this paper are morphologically very similar and thus probably phylogenetically closely related: Nitocrellopsis halsei and $N$. pinderi sp. nov. As mentioned in the introduction section this now makes three sister-species pairs in this group of freshwater subterranean ameirids, the other two being $N$. hellenica Cottarelli \& Forniz, 1993/N. hyppocratis Cottarelli \& Forniz, 1993 from Greece and $N$. ioneli Dumont and Decraemer, 1974/N. ahagarrensis Fiers \& Iliffe, 2000 from Northern Africa (Morocco and Algeria). Because these pairs differ morphologically from each other quite considerably, this was also an excellent opportunity to test the robustness of some morphological characters in phylogenetic analyses of freshwater ameirids. All three pairs have exactly the same armature formula of the swimming legs and they certainly all have the same segmentation, which means that it is not so easy to reduce a segment in a single evolutionary event in this branch of freshwater ameirids, as in some more reduced representatives (see Karanovic and Hancock, 2009). On the other hand, armature of the mouth appendages seems to be less reliable. It is interesting that in two pairs (halesi/pinderi and hellenical hippocratis) sister species differ in the number of setae on the mandibular endopod (four or five), while unfortunately for the third pair the situation cannot be confirmed; Fiers and Iliffe (2000) redescribed $N$. ioneli in detail (although they did not provide any drawings of the mandibula), but for the newly described $N$. ahaggarensis they only stated that "buccal appendages with general appearance and armature as in N. ioneli". All three pairs show differences in the caudal rami shape, which is not so surprising considering that these structures would be under a strong evolutionary pressure, especially when two closely related species (newly diverged) come to live simpatrically. Male copepods grab female caudal rami in the first copulatory act (Huys and Boxshall, 1991), and that is probably where most species-recognition happens in the subterranean environments. That was the main reason I scored no characters from the caudal rami. The fact that the larger form has shorter rami in the sister pair ionelli/ahaggarensis and longer in halsei/pinderi makes is highly improbable that this is a case of intraspecific variability (or dimorphism) and related characters.

I downweighted the Characters 6 and 7 (Table 1; armature of the mandibular and maxillular endopod), because they are different in very closely related species (see above), and Characters 40 and 41 (armature of the fifth leg), because they show intraspecific variability and sometimes are even different as a result of asymmetry. As in some more reduced freshwater ameirids (see Karanovic and Hancock, 2009), the fifth leg seems to hold very few robust characters for reconstructing the phylogenetic relationships among different groups and even within the groups, as it can be highly variable in a single species (see Figs. 4A, 4D, 8G, 8H, 9G in this paper; Cottarelli and Fornitz, 1993, p. 141; Fiers and Iliffe, 2000, p. 87). Of limited value is also the antennal exopod armature
(Character 4), although its segmentation may be a slightly more robust character (Conroy-Dalton and Huys, 1997, 1998). The only ingroup species in our analysis with the reduced antennal exopod armature was $N$. operculata $\mathrm{sp}$. nov. (Fig. 12F), while all the others had three elements (Figs. 5D and 11G), just like the three outgroup taxa. However, the reduced armature was also observed in Parapseudoleptomesochra rouchi Karanovic, 2004, which is only very remotely related to our outgroup from the same genus ( $P$. tureei Karanovic, 2006), while its sister species, P. karamani Karanovic, 2004, has the plesiomorphic armature of this segment (Karanovic, 2004a). Only one more character was downweighted in this analysis, because it was present in only one outgroup and one ingroup and its distribution in the family is quite peculiar: lateral cuticular windows on the genital somite (Character 0). The scanning electron micrographs of $N$. operculata show (Fig. 12A) that the dorsal cuticular windows on the second and third prosomite are expressed also externally, but the lateral ones on the genital and third urosomal somites are not, and yet they are highly visible under a brightfield or phase-interference compound microscopes. This only means that these structures are internal. Although a similar structure is also present in one of the outgroups, Parapseudoleptomesochra tureei, the latter has lateral windows only on the genital somite and no dorsal prosomal windows whatsoever. However these structures are variously expressed in different, and only very remotely related, freshwater ameirid genera (Karanovic, 2006) and may have arisen independently a number of times, as they are absent in more primitive marine species and two other outgroups here. Although, cuticular windows (along with most other somite ornamentation) were not described as such for some species analysed here (N. elegans (Chappuis and Rouch, 1959) and N. petkovskii Rouch, 1987, for example), they were not reported either, and the authors demonstrated that they have closely examined their specimens. Thus, I presume that they are absent (Table 1). Another two very characteristic cuticular structures appear in the genus Nitocrellopsis but were not scored in the cladistic analysis. Enigmatic large, dorsolateral cuticular pores were described by Galassi et al. (1999) from the fifth pedigerous somite of $N$. rouchi Galassi, De Laurentiis \& Dole-Olivier, 1999. Similar structures are present in N. halsei (Fig. 1A), but on the fourth pedigerous somite, and completely absent in its sister-species, $N$. pinderi (Fig. 5A), although the latter is the larger form and they would be easier to observe if present. Cuticular tube pores on the first antennal segment are present in all three newly described species (Figs. 5C, 11D, 11F, 12D and 12E) and similar structures were also reported for N. rouchi by Galassi et al. (1999), but these delicate organs would easily be overlooked in some older descriptions and are variably present/absent in different and unrelated lineages of Australian freshwater ameirids (Karanovic, 2006; Karanovic and Hancock, 2009; Tang and Knott, 2009).

The cladistic analysis resulted in only one tree (Fig. 13) with a length of 65 steps, a consistency index (Ci) of 61 


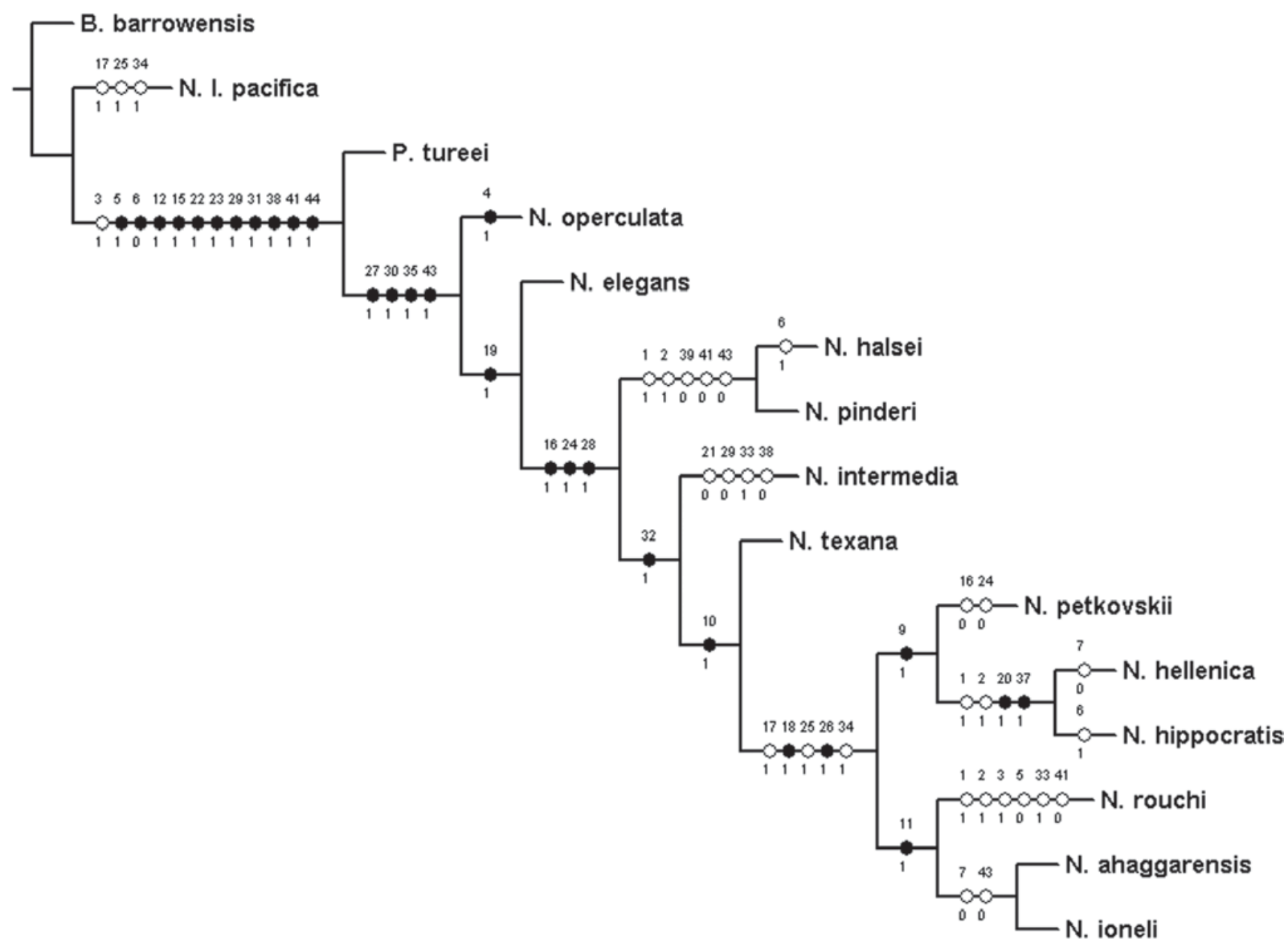

Fig. 13. The only cladogram resulting from analysis of 45 morphological characters (Table 1) scored for 12 Nitocrellopsis Galassi, De Laurentiis \& Dole-Olivier, 1999 species and the three outgroups: Biameiropsis barrowensis Karanovic, 2006, Nitokra lacustris pacifica Yeatman, 1983, and Parapseudoleptomesochra tureei Karanovic, 2006. Full circles - presumable apomorphies; empty circles presumable plesiomorphies; numbers above branches - characters; numbers below branches - character states. See text for more details.

and a retention index (Ri) of 78. The values obtained of the $\mathrm{Ci}$ and $\mathrm{Ri}$ indices indicate a relatively high proportion of convergencies (homoplastic changes), although not as high as in the analysis of more reduced freshwater ameirids done by Karanovic and Hancock (2009). This is obviously a result of the character choices, but it also reflects a general trait within the subterranean freshwater ameirids of an unusual proportion of convergencies within almost any of its groups. The choice of the outgroup taxa was explained in the Material and methods section above and was quite successful.

The cladogram presented above (Fig. 13) shows that the ingroup is well defined by four synapomorphies, one of which concerns the segmentation of the fourth leg endopod (Character 30), two are related to the armature of the third and fourth swimming leg (Characters 27 and 35 respectively), and one to the armature of the female fifth leg (Character 43). The first character was traditionally used to define the genus Nitocrellopsis, since its first mention by Petkovski (1976). As it is evident, two other outgroups are only remotely related to the rest of taxa analysed, but they were very helpful for recognizing homologues structures and correctly polarizing the character states. Biameiropsis barrowensis is an anchialine ameirid with most morphological characters in their plesiomorphic state in this family and will also be a suitable outgroup for any future cladistic analyses of other freshwater ameirid genera. Among other characters, it has an armed antennal basis, mandibular and maxillular exopod, two maxillar endites, an inner seta on the second endopodal segment of the first leg, three-segmented rami on all swimming legs and a very primitive armature formula of the swimming legs and the fifth leg. Most of these were not coded in the matrix, as they would be uninformative. Nitokra lacustris pacifica is a recent invader of the Australian inland waters, otherwise known from crab holes in Western Samoa, Tonga and Fiji, and temporary brackish pools in Papua New Guinea (Karanovic, 2004a).

Nitocrellopsis operculata, which comes from the Western Australian Pilbara region, has a very basal position on the cladogram, as do two sister species from the neighbouring Yilgarn region: $N$. halsei and $N$. pinderi. However, they are only remotely related and most of their similarities are in fact plesiomorphic character state, which are useless for the reconstruction of phylogenetic relationships. Although, they have no close relatives among recent 
Nitocrellopsis species, it would be very hard to justify their separate generic statuses. While $N$. operculata has an autapomorphic armature of the antennal exopod (Character 4), this alone is not a robust generic character, as discussed above. On the other hand, the branch that contains $N$. halsei and $N$. pinderi is completely defined by synplesiomorphies. Two French species, $N$. elegans and $N$. rouchi, are also very remotely related, as are two species from Algeria, $N$. petkovskii and $N$ ahaggarensis, which would all imply an ancient origin of the genus and probably its Tethyan roots, as discussed by Fiers and Iliffe (2000). Although, the genus as currently defined and analysed here appears to be monophyletic, I should mention that none of the forms with more reduced segmentation of the swimming legs were included here and the future revision of the family may expose Nitocrellopsis as paraphyletic. The fact that none of the six basal species (except the sister pair halsei/pinderi) is closely related to each other is a good indicator of this possibility, but this is just a speculation at this stage. The North American N. texana Fiers \& Iliffe, 2000 seems to be most closely related to the Balkan $N$. intermedia Chappuis, 1937, although the latter is known from only a limited set of morphological characters, as is the French N. elegans, and some of their apparent relationships may be a consequence on many unknown characters in the matrix above (Table 1). Other six species form a terminal Mediterranean clade, which is well defined by at least two synapomorphies (Characaters 18 and 26) and what seem to be three synplesiomorphies, although some of the alleged "symplesiomorphies" in this analysis could in fact be series of homoplastic synapomorphies, as an unusual proportion of convergencies is probably a general trait within the subterranean freshwater ameirids. However, this clade is further divided into two subclades. The first one consists of two Greek sister-species, $N$. hellenica and N. hippocratis, and the Algerian N. petkovskii and it is defined by a single apomorphic feature: absence of the any armature on the maxillipedal suncoxa (Character 9). Unfortunately, the state of this character is unknown in two species studied here (N. elegans and intermedia), as well as in many other subterranean ameirids, and thus it will be very hard to evaluate its robustness for the family level revision. What we know from the three sister-species pairs of Nitocrellopsis is that this character shows no intraspecific variability and it is not different within any of the pairs. The most terminal clade on the cladogram (Fig. 13) consists of two North African sister-species $(N$. ioneli and $N$. ahaggarensis) and the French $N$. rouchi. This clade is also defined by a single synapomorphy: the absence of the inner seta on the first endopodal segment of the first leg (Character 11). It has to be mentioned here that the terminal Mediterranean clade and both subcaldes were correctly recognized by Fiers and Iliffe $(2000$, p. 96) by purely intuitive methods and use of only a couple of morphological characters. However, their assumption that $N$. texana forms another clade with $N$. elegans and $N$. intermedia is clearly based on symplesiomorphies and cannot be supported here.

Although one has to assume that the zoogeography of some of the most ancient landscapes on earth would be very complex, what does not stop to amaze are the regional differences in stygofauna assemblages in Australia, and especially those between the neighbouring Pilbara and Murchison regions of Western Australia (see also Karanovic, 2006, 2008). The discovery that Australian regions have different relationships to other Gondwanan areas was already anticipated by Weston and Crisp (1994). Giribet and Edgecombe (2006) showed the importance of looking at small-scale patterns when inferring Gondwanan biogeography for terrestrial invertebrates. Even results of this phylogenetic analysis reinforce this notion, which was already discussed in Karanovic (2006), where I even proposed a "pulsating desert hypothesis" as a novel dynamic model that may explain some of the differences observed. Other, published (Karanovic, 2008; Karanovic and Hancock, 2009) and unpublished research (Karanovic T., Eberhard S.M. and Murdoch A., unpubl. data), done recently on subterranean waters in eastern Australia showed a similar dividing line between the stygofaunas of Queensland and New South Wales, although we are not sure yet where this boarder lies precisely. In short, copepods found in Queensland are more closely related to those from the Western Australian Pilbara region, than to the neighbouring New South Wales. A strong connection between the Pilbara region, tropical Queensland and New Zealand was observed, which may even predate Gondwanan regionality.

Although a key to species of the genus Nitocrellopsis was provided relatively recently by Galassi et al. (1999), with the inclusion of the three new species described in this paper and the two described by Fiers and Iliffe (2000), the number has risen to 12 . Thus, I think, it would be beneficial to provide an updated key here. Note that the characters for this are not only chosen for their convenience but also for their phylogenetic importance whenever possible (see also Fig. 13).

\section{Key to species of the genus Nitocrellopsis Galassi et al., 1999}

1. Exopod of antenna with three elements 2

- Exopod of antenna with two elements ........................................................................... N. operculata sp. nov.

2. Third exopodal segment of second and third leg without inner seta ........... 3

- This segment with inner seta N. elegans (Chappuis and Rouch, 1959)

3. Third exopodal segment of fourth leg with two inner setae 4

- This segment with one or none inner setae 
4. Caudal rami much shorter than anal somite; exopod of fifth leg more than 1.5 times as long as wide

- Caudal rami about as long as anal somite; exopod of fifth leg less than 1.5 times as long as wide

N. halsei sp. nov.

...................... N. pinderi sp. nov.

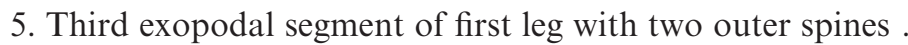

N. intermedia (Chappuis, 1937)
second and third legs unarmed ..

- This segment with three outer spines

6. First endopodal segment of fourth leg and first and second endopodal segments of second and third legs unarmed ..

- All these segments with inner seta

N. texana Fiers \& Iliffe, 2000

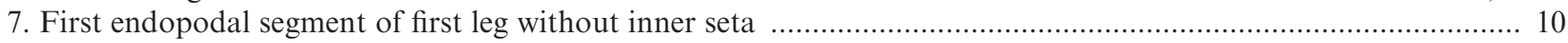

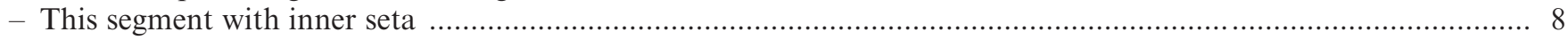

8. Ultimate endopodal segments of second and fourth legs with single element ............................................. 9

- These segments with two elements .............................................................................. N. petkovskii Rouch, 1987

9. Caudal rami cylindrical; endopod of mandibula with five setae ................... N. hellenica Cottarelli \& Forniz, 1993

- Caudal rami conical, endopod of mandibula with four setae .................... N. hippocratis Cottarelli \& Forniz, 1993

10. Genital somite in female fused ventrally with third urosomal

- Genital somite free

N. rouchi Galassi, De Laurentiis \& Dole-Olivier, 1999

11. Caudal rami longer and more cylindrical N. ioneli (Dumont and Decraemer, 1974)

- Caudal rami short and conical N. ahaggarensis Fiers \& Iliffe, 2000

Acknowledgements. This work was partly financially supported by the Western Australian Department of Environment and Conservation (DEC). I thank Dr. Stuart Halse who organized the DEC grant and Dr. Adrian Pinder who executed it. Ms. Renate Walter, from the Hamburg Museum, is kindly acknowledged for the help in preparation of the SEM photographs. Special thanks to Mr. Jim Cocking and Mr. Mike Scanlon, both from Bennelongia Pty Ltd, for collecting this interesting material. Dr. Rony Huys, from the Natural History Museum in London, kindly commented on the first draft of the manuscript and comments of the two anonymous referees greatly improved this paper.

\section{References}

Chappuis P.A., 1924. Descriptions préliminaires de Copépodes nouveaux de Serbie. Buletinul Societatii de Stiinte din Cluj, Romania, 2, 27-45.

Chappuis P.A., 1937. Weitere subterrane Harpacticiden aus Jugoslavien. Buletinul Societătiii de Stiinţte din Cluj, 8, 503-532.

Chappuis P.A. and Rouch R., 1959. Harpacticoides cavernicoles des Basses-Pyrénées. Annales de Spéléologie, 14, 197-211.

Cho J.-L., Humphreys W.F. and Lee S.-D., 2006a. Phylogenetic relationships within the genus Atopobathynella Schminke, 1973 (Bathynellacea, Parabathynellidae): with the description of six new species from Western Australia. Invert. Syst., 20, 9-41.

Cho J.-L., Park J.-G. and Ranga Reddy Y., 2006 b. Brevisomabathynella gen. nov. with two new species from Western Australia (Bathynellacea, Syncarida): the first definitive evidence of predation in Parabathynellidae. Zootaxa, 1247, 25-42.

Conroy-Dalton S. and Huys R., 1997. Towards a revision of Ameira Boeck, 1865 (Harpacticoida, Ameiridae): reexamination of the $A$. tenella-group and the establishment of Filexilia gen. n. and Glabrameira gen. n. Zool. Scr., 25, 317-339.
Conroy-Dalton S. and Huys R., 1998. Towards a revision of Ameira Boeck, 1865 (Harpacticoida, Ameiridae): reinstatement of Psammameira Noodt, 1952. Zool. Scr., 27, 247-261.

Cooper S.J.B., Saint K.M., Taiti S., Austin A.D. and Humphreys W.F., 2008. Subterranean archipelago: mitochondrial DNA phylogeography of stygobitic isopods (Oniscidea: Halniscus) from the Yilgarn region of Western Australia. Invert. Syst., 22, 195-203.

Cottarelli V. and Forniz O., 1993. Due nuove species di Nitocrellopsis Petkowski di acque freatiche delle isole di Kos e Tilos (Sporadi Meridionali) (Crustacea, Copepda, Harpacticoida). Fragmenta Entomologica, Roma, 24, 131-145.

De Laurentiis P., Pesce G.L. and Humphreys W.F., 1999. Copepods from ground waters of Western Australia, IV. Cyclopoids from basin and craton aquifers (Crustacea: Copepoda: Cyclopidae). Records of the Western Australian Museum, 19, 243-257.

De Laurentiis P., Pesce G.L. and Humphreys W.F., 2001. Copepods from ground waters of Western Australia, VI. Cyclopidae (Crustacea: Copepoda) from the Yilgarn Region and the Swan Coastal Plain. Records of the Western Australian Museum, Supplement, 64, 115-131.

Dumont H.J. and Decraemer W., 1974. Nitocrella ioneli n. sp. (Crustacea: Copepoda), a new phreatic harpacticoid copepod from the Presahara in Morocco. Biologische Jahrbuche Dodonaea, 42, 105-111.

Fiers F. and Iliffe T.M., 2000. Nitocrellopsis texana n. sp. from central TX (U.S.A.) and $N$. ahaggarensis n. sp. from the sentral Algerian Sahara (Copepoda, Harpacticoida). Hydrobiologia, 418, 81-97.

Finston T.L., Johnson M.S., Humphreys W.F., Eberhard S. and Halse S., 2007. Cryptic speciation in two widespread amphipod genera reflects historical drainage patterns in an ancient landscape. Mol. Ecol., 16, 355-365.

Galassi D.M., De Laurentiis P. and Dole-Olivier M.-J., 1999. Nitocrellopsis rouchi sp. n., a new ameirid harpacticoid from phreatic waters in France (Copepoda; Harpacticoida: Ameiridae). Hydrobiologia, 412, 177-189. 
Giribet G. and Edgecombe G.D., 2006. The importance of looking at small-scale patterns when inferring Gondwanan biogeography: a case study of the centipede Paralamyctes (Chilopoda, Lithobiomorpha, Henicopidae). Biol. J. Linn. Soc., 89, 65-78.

Goloboff P., 1999. NONA (NO NAME) version 2, Tucumán, Argentina: Published by the author.

Guzik M., Abrams K.M., Cooper S.J.B., Humphreys W.F., Cho J.-L. and Austin A.D., 2008. Phylogeography of the ancient Parabathynellidae (Crustacea: Bathynellacea) from the Yilgarn region of Western Australia. Invert. Syst., 22, 205-216.

Humphreys W.F., 2000. Background and glossary. In: Wilkens H., Culver D.C. and Humphreys W.F. (eds.), Ecosystems of the World, 30, Subterranean Ecosystems, Elsevier, Amsterdam-Lausanne-New York-Oxford-Shannon-SingaporeTokyo, 3-14.

Humphreys W.F., 2001. Groundwater calcrete aquifers in the Australian arid zone: the context to an unfolding plethora of stygal biodiversity. Records of the Western Australian Museum, Supplement, 64, 63-83.

Humphreys W.F., 2006. Aquifers: the ultimate groundwaterdependent ecosystems. Aust. J. Bot., 54, 115-132.

Humphreys W.F., 2008. Rising from Down Under: developments in subterranean biodiversity in Australia from a groundwater perspective. Invert. Syst., 22, 85-101.

Huys R., 2009. Unresolved cases of type fixation, synonymy and homonymy in harpacticoid copepod nomenclature (Crustacea: Copepoda). Zootaxa, 2183, 1-99.

Huys R. and Boxshall G.A., 1991. Copepod Evolution, The Ray Society, London.

ICZN, 1999. The International Trust for Zoological Nomenclature, Fourth edition, London.

Jaume D. and Humphreys W.F., 2001. A new genus of epacteriscid calanoid copepod from an anchialine sinkhole in northwestern Australia. J. Crust. Biol., 21, 157-169.

Jaume D., Boxshall G.A. and Humphreys W.F., 2001. New stygobiont copepods (Calanoida; Misophrioida) from Bundera sinkhole, an anchialine cenote on north-western Australia. Zool. J. Linn. Soc. Lond., 133, 1-24.

Karanovic I., 2007. Candoninae ostracods from the Pilbara region in Western Australia. Crustaceana Monographs, 7, $1-432$.

Karanovic T., 2003. First representative of the genus Allocyclops Kiefer, 1932 (Crustacea, Copepoda, Cyclopoida) from the Australian subterranean waters. Ann. Limnol. - Int. J. Lim., 39, 141-149.

Karanovic T., 2004a. Subterranean Copepoda from arid Western Australia. Crustaceana Monographs, 3, 1-366.

Karanovic T., 2004b. The genus Metacyclops Kiefer in Australia (Crustacea: Copepoda: Cyclopoida), with description of two new species. Records of the Western Australian Museum, 22, 193-212.

Karanovic T., 2005. Two new subterranean Parastenocarididae (Crustacea, Copepoda, Harpacticoida) from Western Australia. Records of the Western Australian Museum, 22, 353-374.

Karanovic T., 2006. Subterranean copepods (Crustacea, Copepoda) from the Pilbara region in Western Australia. Records of the Western Australian Museum, Supplement, 70, 1-239.

Karanovic T., 2008. Marine interstitial Poecilostomatoida and Cyclopoida (Copepoda) of Australia. Crustaceana Monographs, 9, 1-331.
Karanovic T. and Eberhard S.M., 2009. Second representative of the order Misophrioida (Crustacea, Copepoda) from Australia challenges the hypothesis of the Tethyan origin of some anchialine faunas. Zootaxa, 2059, 51-68.

Karanovic T. and Hancock P., 2009. On the diagnostic characters of the genus Stygonitocrella (Copepoda, Harpacticoida), with descriptions of seven new species from Australian subterranean waters. Zootaxa, 2324, 1-85.

Karanovic T. and Pesce G.L., 2002. Copepods from ground waters of Western Australia, VII. Nitokra humphreysi sp. nov. (Crustacea: Copepoda: Harpacticoida). Hydrobiologia, $470,5-12$.

Karanovic T. and Tang D., 2009. A new species of the copepod genus Australoeucyclops (Crustacea: Copepoda: Eucyclopinae) from Western Australia shows the role of aridity in habitat shift and colonization of ground water. Records of the Western Australian Museum, 25, 247-263.

Karanovic T., Pesce G.L. and Humphreys W.F., 2001. Copepods from ground waters of Western Australia, V. Phyllopodopsyllus wellsi sp. nov. (Crustacea: Copepoda: Harpacticoida) with a key to world species. Records of the Western Australian Museum, 20, 333-344.

Lang K., 1965. Copepoda Harpacticoida from the Californian Pacific Coast. Kungl. Svenska Vetenskapsakad. Handl., 10, $1-560$.

Lee W. and Huys R., 2002. A new genus of groundwater Ameiridae (Copepoda, Harpacticoida) from boreholes in Western Australia and the artificial status of Stygonitocrella Petkovski, 1976. Bulletin of the Natural History Museum, London (Zoology), 68, 39-50.

Leys R. and Watts C.H., 2008. Systematics and evolution of the Australian subterranean hydroporine diving beetles (Dytiscidae), with notes on Carabhydrus. Invert. Syst., 22, 217-225.

Leys R., Watts C.H.S., Cooper S.J.B. and Humphreys W.F., 2003. Evolution of subterranean diving beetles (Coleoptera: Dytiscidae: Hydroporini, Bidessini) in the arid zone of Australia. Evolution, 57, 2819-2834.

Michailova-Neikova M., 1964. Contribution to the study of fresh water harpacticoid fauna in Bulgaria. Annuaire de l'Université de Sofia, Faculté de Biologie, 58, 75-85 [in Bulgarian with English summary].

Nicholls A.G., 1945a. Marine Copepoda from Western Australia, 4. Psammophilous harpacticoids. Journal of the Royal Society of Western Australia, 29, 17-24.

Nicholls A.G., 1945b. Marine Copepoda from Western Australia, 5. A new species of Paramesochra, with an account of a new harpacticoid family, the Remaneidae, and its affinities. Journal of the Royal Society of Western Australia, 29, 91-105.

Nixon K.C., 2002. WinClada version 1.00.08, Ithaca, New York: Published by the author.

Pesce G.L. and De Laurentiis P., 1996. Copepods from ground waters of Western Australia, III. Diacyclops humphreysi n. sp. and comments on the Diacyclops crassicaudis complex (Copepoda, Cyclopidae). Crustaceana, 69, 524-531.

Pesce G.L., De Laurentiis P. and Humphreys W.F., 1996a. Copepods from ground waters of Western Australia, I. The genera Metacyclops, Mesocyclops, Microcyclops and Apocyclops (Crustacea: Copepoda: Cyclopidae). Records of the Western Australian Museum, 18, 67-76. 
Pesce G.L., De Laurentiis P. and Humphreys W.F., 1996b. Copepods from ground waters of Western Australia, II. The genus Halicyclops (Crustacea: Copepoda: Cyclopidae). Records of the Western Australian Museum, 18, 77-85.

Petkovski T.K., 1976. Drei neue Nitocrella-Arten von Kuba, zugleich eine Revision des Genus Nitocrella Chappuis (s. restr.) (Crustacea, Copepoda, Ameiridae). Acta Musei Macedonici Scientiarum Naturalium, 15, 1-26.

Reid J.W., Hunt G.W. and Stanley E.H., 2003. A new species of Stygonitocrella (Crustacea: Copepoda: Ameiridae), the first report of the genus in North America. Proceedings of the Biological Society of Washington, 116, 996-1006.

Rouch R., 1964. Note sur les Harpacticides, 1 - Une nouvelle Elaphoidella de l'Ariège; 2 - Description des males de Nitocrella gracilis et Nitocrella elegans. Annales de Spéléologie, 19, 525-531.

Rouch R., 1987. Copépodes Harpacticoïdes stygonies d'Algérie. Bijdragen tot de Dierkunde, 57, 71-86.

Stock J.K. and von Vaupel Klein J.C., 1996. Mounting media revisited: the suitability of Reyne's fluid for small crustaceans. Crustaceana, 69, 749-798.

Suárez-Morales E. and Iliffe T.M., 2005. A new Stygonitocrella Petkovski (Copepoda: Harpacticoida) from a cave in
Northern Mexico with comments on the taxonomy of the genus. Hydrobiologia, 544, 215-228.

Tang D. and Knott B., 2009. Freshwater cyclopoids and harpacticoids (Crustacea: Copepoda) from the Gnangara Mound Region of Western Australia. Zootaxa, 2029, 1-70.

Tang D., Barron H. and Goater S., 2008. A new genus and species of Ridgewayiidae (Copepoda: Calanoida) from subterranean waters of northwestern Australia. J. Crust. Biol., 28, 551-563.

Watts C.H.S and Humphreys W.F., 2006. Twenty-six new Dytiscidae (Coleoptera) of the genera Limbodessus Guignot and Nirripirti Watts and Humphreys, from underground waters in Australia. Transactions of the Royal Society of South Australia, 130, 123-185.

Wells J.B.J., 2007. An annotated checklist and keys to the species of Copepoda Harpacticoida. Zootaxa, 1568, $1-872$.

Weston P.H. and Crisp M.D., 1994. Cladistic biogeography of waraths (Proteaceae: Embothrieae) and their allies across the Pacific. Austral. Syst. Bot., 7, 225-249.

Wilson G.D.F., 2008. Gondwanan groundwater: subterranean connections of Australian phreatoicidean isopods to India and New Zealand. Invert. Syst., 22, 301-310. 